\title{
The Effect of Topography on Storm-Track Intensity in a Relatively Simple General Circulation Model
}

\author{
SEOK-WOO SON \\ Department of Applied Physics and Applied Mathematics, Columbia University, New York, New York \\ MingFANG TING \\ Lamont-Doherty Earth Observatory, Palisades, New York \\ LORENZO M. POLVANI \\ Department of Applied Physics and Applied Mathematics, and Department of Earth and Environmental Sciences, \\ Columbia University, New York, New York
}

(Manuscript received 16 January 2008, in final form 2 July 2008)

\begin{abstract}
The effect of topography on storm-track intensity is examined with a set of primitive equation model integrations. This effect is found to be crucially dependent on the latitudinal structure of the background flow impinging on the topography. If the background flow consists of a weak double jet, higher topography leads to an intensification of the storm track downstream of the topography, consistent with enhanced baroclinicity in that region. However, if the background flow consists of a strong single jet, topography weakens the storm track, despite the fact that the baroclinicity downstream of the topography is again enhanced.

The different topographic impact results from the different wave packets in the two background flows. For a weak double-jet state, wave packets tend to radiate equatorward and storm-track eddies grow primarily at the expense of local baroclinicity. In contrast, for a strong single-jet state, wave packets persistently propagate in the zonal direction and storm tracks are affected not only by local baroclinicity but also by far-upstream disturbances via downstream development. It is the reduction of the latter by the topography that leads to weaker storm tracks in a strong single-jet state. The implications of these findings for Northern Hemisphere storm tracks are also discussed.
\end{abstract}

\section{Introduction}

Two distinct storm tracks are observed in the Northern Hemisphere ( $\mathrm{NH})$ winter: one over the Pacific and the other over the Atlantic Ocean sector. They are located downstream of the jets where the baroclinicity reaches a maximum (Blackmon 1976; Frederiksen 1983), suggesting that storm tracks are primarily organized by baroclinic eddy activity. The relationship between local baroclinicity and storm-track intensity, however, is not well understood. For example, the Pacific storm track is generally weaker than the Atlantic

Corresponding author address: Seok-Woo Son, Department of Atmospheric and Oceanic Sciences, McGill University, 805 Sherbrooke St. West, Montreal, QC H3A 2K6, Canada.

E-mail: seok-woo.son@mcgill.ca storm track, even though baroclinicity is stronger over the Pacific [see Chang et al. (2002) for a review]. A similar anticorrelated relationship is also found in the seasonal variation of the Pacific storm track: it is weaker during midwinter when the baroclinicity is a maximum (Nakamura 1992). This midwinter suppression of the storm track, however, is rarely observed in the Atlantic sector.

The seemingly puzzling relationship described above is partly due to the fact that storm-track eddies grow not only by local instability but also by recycling eddies located far upstream (Pierrehumbert 1984; Orlanski and Katzfey 1991; Chang and Orlanski 1993). Chang and Orlanski indicated that significant eddy activity can betriggered over the relatively weak baroclinic region by the energy advected from upstream regions. This so-called upstream eddy seeding-feeding process, or downstream 
development, results in storm tracks that are much stronger and wider than those expected from local baroclinic energy conversion.

In the atmosphere, storm tracks are affected by many factors, such as background flow, topography, land-sea contrast, and diabatic heating. These factors can affect storm-track intensity by modifying local baroclinicity, the efficiency of downstream development, and the energy source for storm-track eddies. Lee and Mak (1996) have suggested that topography, among many other factors; may explain up to $70 \%$ of the observed stormtrack intensity for a given background flow. This result appears to be contradictory to the Hoskins and Valdes (1990) study, which indicated that storm tracks are largely maintained by diabatic heating. However, the fact that diabatic heating downstream of the topography partially owes its existence to the updraft driven by orographic waves suggests that topography may still play a crucial role.

The role of topography on the maintenance of stationary waves has been extensively studied in the past (e.g., Nigam et al. 1988; Valdes and Hoskins 1991; Ting et al. 2001; Held et al. 2002; among others). However, the topographic impact on storm tracks has rarely been examined. Although a few studies can be found in the literature (e.g., Broccoli and Manabe 1992; Lee and Mak 1996), it is presently unclear how topography modifies storm-track intensity. All previous studies were based on either very idealized or fully comprehensive numerical models. Lee and Mak utilized a dry, three-layer, balanced model in which a realistic topography is imposed on the zonally symmetric background flow. Although it is more realistic than a two-layer model in which local baroclinicity is prescribed (e.g., Pierrehumbert 1984; Whitaker and Dole 1995; ZuritaGotor and Chang 2005), the crude vertical and horizontal representation of eddies makes quantitative estimates questionable. On the other hand, Broccoli and Manabe (1992) compared storm tracks in their comprehensive general circulation model (GCM) integrations with and without topography. While valuable insights were obtained, they were not able to separate the topographic effect from the effect of changes in diabatic heating due to the different topography.

In this study, the dynamical effect of topography on storm-track intensity is examined with a multilayer primitive equation model. Although idealized, this model is much more realistic than two- or three-layer models. It also allows us to test the topographic effect explicitly since diabatic heating and other physics are excluded. Using such a model, a parameter study is carried out by varying both the background flow and the properties of the topography (e.g., height, shape, and location). It is found that although topography always strengthens the downstream baroclinicity, the resulting storm tracks can be either stronger or weaker than without topography, depending on the latitudinal structure of the background flow. Since similar positive and negative relationships between local baroclinicity and storm-track intensity are also observed in the $\mathrm{NH}$, our results offer a potential explanation for the puzzling relationship between them in the atmosphere.

This paper is organized as follows: The numerical model and the experimental design are described in section 2. In section 3, we present the storm tracks and related fields in the base integrations. In sections 4 and 5 , the role of topography in storm-track intensity is diagnosed in detail. A summary and conclusions are given in section 6 , with possible implications for the real atmosphere.

\section{Model and experimental design}

We use a set of model integrations that are described in details in Son et al. (2008). The numerical model is a global pseudospectral primitive equation model, based on the dynamical core of the Geophysical Fluid Dynamics Laboratory GCM (hereafter referred to as a simple GCM). It is truncated into the rhomboidal 30 resolution with 10 equally spaced sigma levels. This model is forced by relaxing the temperature toward an equilibrium temperature profile $T_{e}$ as a function of latitude and pressure, with a constant time scale of 30 days, and is dissipated by surface friction and eighth-order hyperdiffusion. It is integrated to 5500 days; the last 5000 days are used for the analysis.

Two distinct $T_{e}$ profiles are used for the base integrations: one with relatively cold high latitudes (Fig. 1a) and the other with very warm tropics (Fig. 1c). ${ }^{1}$ They are identical to the climate states 2 and 6 in Son et al. (2008) and are chosen to generate two different background flows that are qualitatively similar to the observed westerly jets. The zonal-mean zonal wind resulting from model integrations without topography are shown in Figs. 1b,d for each $T_{e}$ forcing. A weak doublejet state is found for $T_{e}$ forcing in Fig. 1a (referred to as

\footnotetext{
${ }^{1}$ The mathematical form of $T_{e}$ profile can be found in Eq. (1) of Son and Lee (2005). The $T_{e}$ shown in Fig. 1a corresponds to the case with $\hat{h}=5 / 30\left(\mathcal{H}=5 / 3 \mathrm{~K} \mathrm{day}^{-1}\right)$ and $\hat{c}=1 / 30(C=1 / 6 \mathrm{~K}$ day $\left.^{-1}\right)$, whereas that in Fig. 1c corresponds to the case with $\hat{h}=1 /$ $30\left(\mathcal{H}=1 / 3 \mathrm{~K} \mathrm{day}^{-1}\right)$ and $\hat{c}=5 / 30\left(C=5 / 6 \mathrm{~K} \mathrm{day}^{-1}\right)$. See Son and Lee (2005) for the definition of symbols.
} 

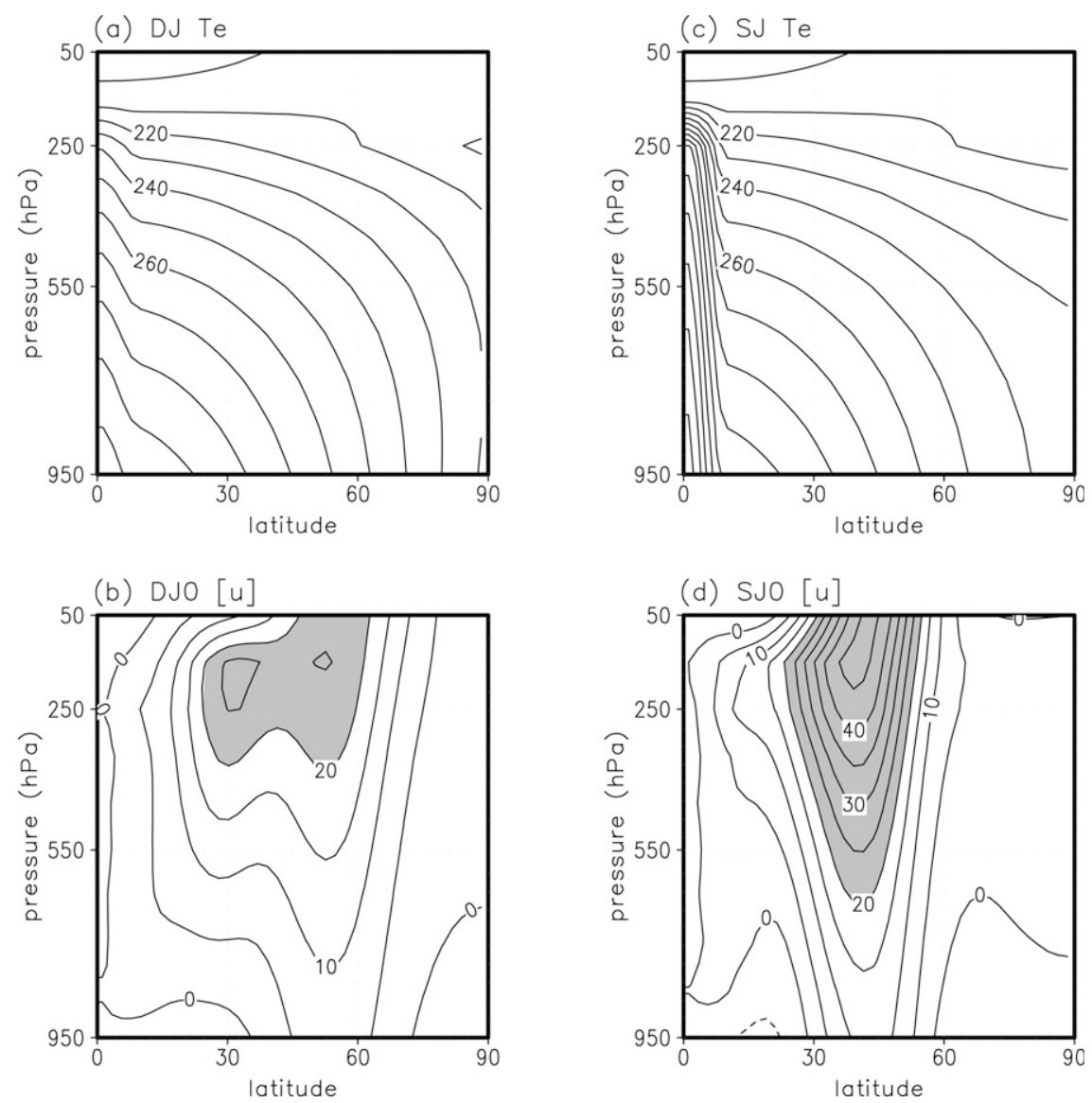

FIG. 1. (a), (c) $T_{e}$ profiles and (b), (d) resulting zonal-mean zonal wind for the (a), (b) DJ0 and (c), (d) SJ0 integrations. Contour intervals (CIs) are (a), (c) $10 \mathrm{~K}$ and (b), (d) $5 \mathrm{~m} \mathrm{~s}^{-1}$; zonal wind equal to and greater than $20 \mathrm{~m} \mathrm{~s}^{-1}$ is shaded. Note that only model NH is presented here since the $T_{e}$ forcing is symmetric about the equator.

DJ forcing), whereas a strong single-jet state is obtained for $T_{e}$ forcing in Fig. 1c (SJ forcing).

The effect of topography is examined by introducing a simple bell-shaped mountain at the model surface boundary. The mountain ${ }^{2}$ is placed at $45^{\circ} \mathrm{N}, 90^{\circ} \mathrm{E}$ (see the thick solid contour lines in the right column of Fig. 2) and its height is varied from 0 (no topography) to

${ }^{2}$ The mountain is generated with cosine functions:

$$
\begin{aligned}
Z= & h \cos \left[\frac{2 \pi}{180} \min \left(\frac{\left|\lambda-\lambda_{o}\right|}{W_{\lambda}}, 45^{\circ}\right)\right] \\
& \times \cos \left[\frac{4 \pi}{180} \min \left(\frac{\left|\varphi-\varphi_{o}\right|}{W_{\varphi}}, 22.5^{\circ}\right)\right],
\end{aligned}
$$

where $h$ is the mountain height, and $\lambda$ and $\varphi$ are the longitude and latitude in degrees. In the base integrations $\varphi_{o}, \lambda_{o}$ are set to $45^{\circ} \mathrm{N}$, $90^{\circ} \mathrm{E}$. The parameters $W_{\lambda}$ and $W_{\varphi}$ control the width of the mountain and are set to 1 except for sensitivity integrations.
$4 \mathrm{~km}$ with a $1-\mathrm{km}$ interval. A total of ten base integrations, five integrations for each $T_{e}$ forcing, are carried out. These integrations are denoted with an acronym that comprises a background $T_{e}$ forcing and mountain height [e.g., DJ0 for the integration with DJ forcing and no mountain (Fig. 1b) and SJ2 for the integration with SJ forcing and a 2-km-high mountain]. Several sensitivity tests are also carried out for the DJ2 and SJ2 integrations by altering the shape and location of the mountain, such as reducing the latitudinal or longitudinal width of the mountain by half and moving the mountain $10^{\circ}$ south or north. These sensitivity integrations are denoted by the acronym DJ2 or SJ2 followed by WE, NS, @35, or@55; for example, DJ2WE indicates the DJ2 integration with a narrow mountain in the westeast direction, and SJ2@35 the SJ2 integration with a mountain at $35^{\circ} \mathrm{N}$. Finally, sensitivity tests are further carried out for different $T_{e}$ forcings with and without topography. 

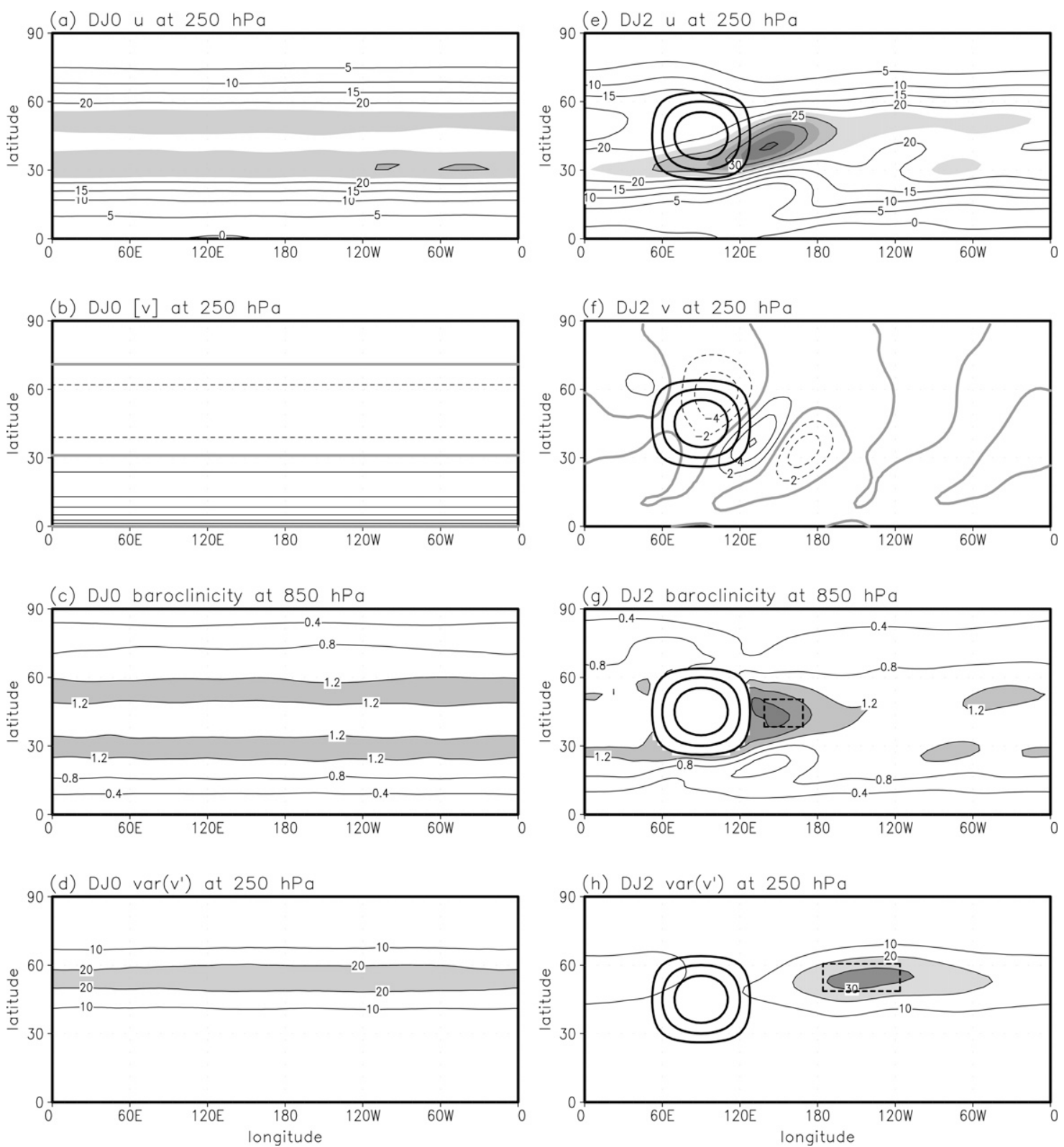

FIG. 2. Time-mean flow for the (a)-(d) DJ0 and (e)-(h) DJ2 integrations: (top row) zonal wind at $250 \mathrm{hPa}\left(\mathrm{CI}=5 \mathrm{~m} \mathrm{~s}{ }^{-1}\right.$; shading for $22.5 \mathrm{~m} \mathrm{~s}^{-1}$ and larger values); (second row) meridional wind at $250 \mathrm{hPa}$ [CI $=0.2 \mathrm{~m} \mathrm{~s}^{-1}$ for (b) and $2.0 \mathrm{~m} \mathrm{~s}^{-1}$ for (f), with thick gray lines for zero wind]; (third row) baroclinicity at $850 \mathrm{hPa}\left(\mathrm{CI}=0.4 \mathrm{day}^{-1}\right.$; shading for $1.2 \mathrm{day}^{-1}$ and larger values); and (bottom row) storm-track intensity at $250 \mathrm{hPa}\left(\mathrm{CI}=10 \mathrm{~m}^{2} \mathrm{~s}^{-2}\right.$; shading for $20 \mathrm{~m}^{2} \mathrm{~s}^{-2}$ and larger values). Thick solid lines in the left column denote topography $(\mathrm{CI}=500 \mathrm{~m}$ beginning at $500 \mathrm{~m})$. In (b) the meridional wind is averaged in the zonal direction to remove noise.

\section{Base integrations}

Prior to presenting the results regarding storm tracks, we briefly describe the characteristics of mean flows in the DJ0 and SJ0 integrations (Figs. 1b,d). As stated before, the overall pattern and strength of jets are quite different in the two integrations. A weak double-jet state is found in the DJ0 integration. In contrast, a strong single-jet state emerges in the SJ0 integration. The dynamics of these two different jets are discussed in full detail in Son and Lee (2005, hereafter SL05). We stress here that these two background flows are qualitatively similar to the observed jets during $\mathrm{NH}$ winter: that is, a relatively weak double jet over the North 
Atlantic and a strong single jet over the northwestern Pacific. Although the observed westerly jets and storm tracks may not be fully understood by zonal-mean dynamics, this similarity is encouraging with regard to the applications to $\mathrm{NH}$ storm tracks.

\section{a. Double-jet (DJO and DJ2) integrations}

Time-mean flows for the DJ0 integration are exhibited in the left column of Fig. 2. From top to bottom, the zonal wind at $250 \mathrm{hPa}$, meridional wind at $250 \mathrm{hPa}$, baroclinicity at $850 \mathrm{hPa}$ measured by the Eady parameter [ $(f / N) d U / d z$, where all symbols are standard], and storm tracks at $250 \mathrm{hPa}$ are displayed. In this study, storm tracks are defined by the variance of bandpassfiltered eddy meridional wind: a Fourier filter, which allows signals between 2 and 7 days only, is applied to the daily meridional wind fields.

The westerly jets in the DJ0 integration show two local maxima (Fig. 2a, see also Fig. 1b): one at $30^{\circ} \mathrm{N}$ and the other at $55^{\circ} \mathrm{N}$. The former is a subtropical jet, as can be inferred from its location at the poleward boundary of the Hadley cell (Fig. 2b). The latter is a polar-front or eddy-driven jet as it forms at the center of the Ferrel cell corresponding to the maximum eddy activity (Fig. 2b). Consistent with these two distinct westerly jets, the baroclinicity in the lower troposphere shows two local maxima (Fig. 2c). Here, a peak in the subtropics is due to potential temperature homogenization by the Hadley cell (e.g., Lee and Kim 2003). Since the associated eddy activities are much weaker than those corresponding to the polar-front jet, storm tracks are formed only in midlatitudes (Fig. 2d).

The effect of topography on the time-mean flow and storm-track intensity is illustrated with a nearly identical integration, performed with a 2-km high mountain, shown in the right column of Fig. 2. In the presence of topography (thick contour lines), the subtropical and polar-front jets are combined with each other and, more importantly, strengthened downstream of the topography (Fig. 2e). These changes in jet structure are associated with stationary waves (Fig. 2f) that enhance the vertical wind shear downstream of the topography (Fig. 2g). Consistent with this strengthening of the jet and baroclinicity, the storm tracks are also strengthened (Fig. 2h).

\section{b. Single-jet (SJO and SJ2) integrations}

An opposite result is found in the SJ integrations, shown in Fig. 3. In the absence of topography a strong single jet (Fig. 3a), which is a mixture of subtropical and polar-front jets, accompanies strong baroclinicity (Fig. 3c). It results in strong storm tracks (Fig. 3d). When a $2-\mathrm{km}$ high mountain is added, the westerly jet is again strengthened (Fig. 3e), consistent with enhanced baroclinicity downstream of the topography (Fig. 3g). These changes in the mean flow are qualitatively similar to those in the DJ integrations. However, the storm-track response is quite different. In spite of the strengthened baroclinicity (Fig. 3g), the intensity of the storm tracks is reduced by almost half (Fig. 3h). These results, combined with the above results in the DJ integrations, indicate that the effect of topography on storm-track intensity is highly dependent on the background flows.

It should be noted that the stationary waves in the two integrations are quite different. While the stationary waves in the DJ2 integration arch equatorward (Fig. 2f), those in the SJ2 integration are confined to the jet (Fig. 3f). The latter results from the wave guiding effect of the strong jet (e.g., Hoskins and Ambrizzi 1993).

\section{c. Summary of the base integrations}

The opposite impacts of topography on the DJ and SJ storm tracks are further validated by model integrations with higher or lower topography. The results are summarized in Figs. 4a,c. In all DJ integrations, storm tracks are strengthened by topography (Fig. 4a); they are to some degree positively correlated with topographically enhanced baroclinicity. The opposite relationship, however, is found in the SJ integrations (Fig. 4c). The storm tracks in all SJ integrations with topography are weaker than those without topography.

\section{Eddy kinetic energy spectra}

It could be argued that the weakening in storm tracks in the SJ integrations is simply due to the energy partitioning between stationary and transient eddies. Assuming that total eddy kinetic energy is conserved, the strengthening in stationary eddies associated with increasing mountain height would result in a weakening of transient eddies, yielding a weaker storm track. The relative contribution of stationary and transient eddies to the total eddy kinetic energy (EKE) at $250 \mathrm{hPa}$ is presented in Fig. 5 for the SJ integrations. It is found that stationary EKE, indeed, increases with topography and appears to be saturated in the SJ2 integration, ${ }^{3}$ consistent with weakening of storm tracks in Fig. 4c.

The above consistency, however, does not explain

\footnotetext{
${ }^{3}$ Although this nonlinear equilibrium is an interesting subject to examine, it is beyond the scope of this study. We simply note here that similar saturation of stationary EKE with increasing mountain height has been found in previous studies (Cook and Held 1992; Yu and Hartmann 1995).
} 

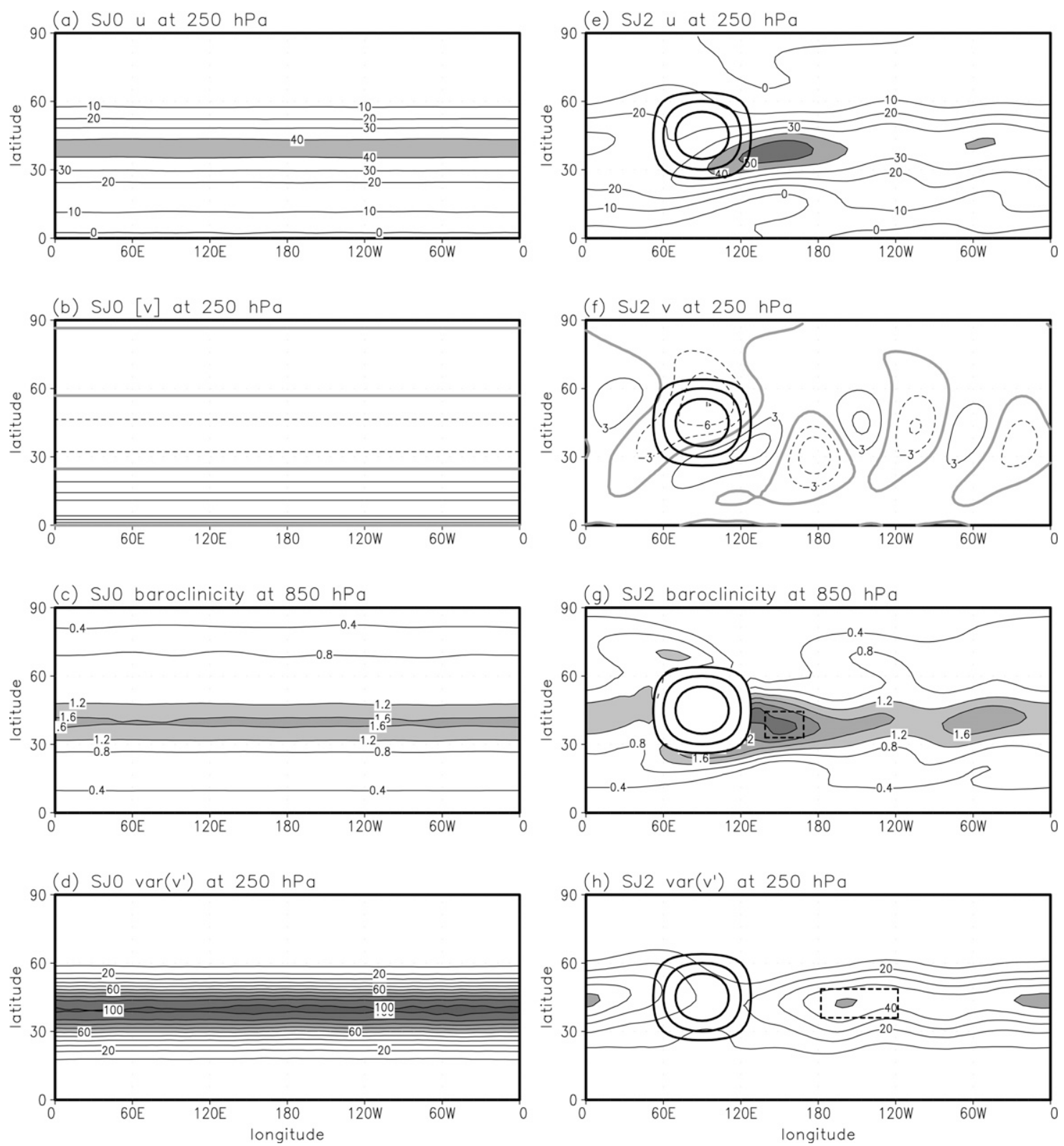

FIG. 3. As in Fig. 2 but for the (a)-(d) SJ0 and (e)-(h) SJ2 integrations: (top row) $\mathrm{CI}=10 \mathrm{~m} \mathrm{~s}^{-1}$; shading for $40 \mathrm{~m} \mathrm{~s}^{-1}$ and larger values; (second row) $\mathrm{CI}=0.3 \mathrm{~m} \mathrm{~s}^{-1}$ for (b) and $3.0 \mathrm{~m} \mathrm{~s}^{-1}$ for (f); (third row) $\mathrm{CI}=0.4 \mathrm{day}^{-1}$; shading for 1.2 day $^{-1}$ and larger values; and (bottom row) $\mathrm{CI}=10 \mathrm{~m}^{2} \mathrm{~s}^{-2}$; shading for $50 \mathrm{~m}^{2} \mathrm{~s}^{-2}$ and larger values.

the sharp decrease of storm-track intensity in the SJ integrations. Although transient EKE is reduced by topography, this change is much less dramatic than those seen in the storm-track intensity. For instance, in Fig. 5, total EKE does not change at all as mountain height increases from 1 to $2 \mathrm{~km}$ (filled squares). In addition, the energy partitioning argument is not able to explain the local intensification of storm tracks in the DJ integrations. These results indicate that storm-track intensity is controlled by other processes.
The emerging question in Fig. 5 is why total EKE does not change from the SJ1 to SJ2 integrations even when the bandpass filtered EKE decreases substantially. Although this study is focused on the storm-track eddies, it is worth discussing how EKE spectra are affected by topography. Figure 6 illustrates latitudinally integrated EKE power spectra as a function of longitude and frequency. To emphasize the topographic effect, EKE spectra for the topography integrations are normalized by those in the control integrations; hence 

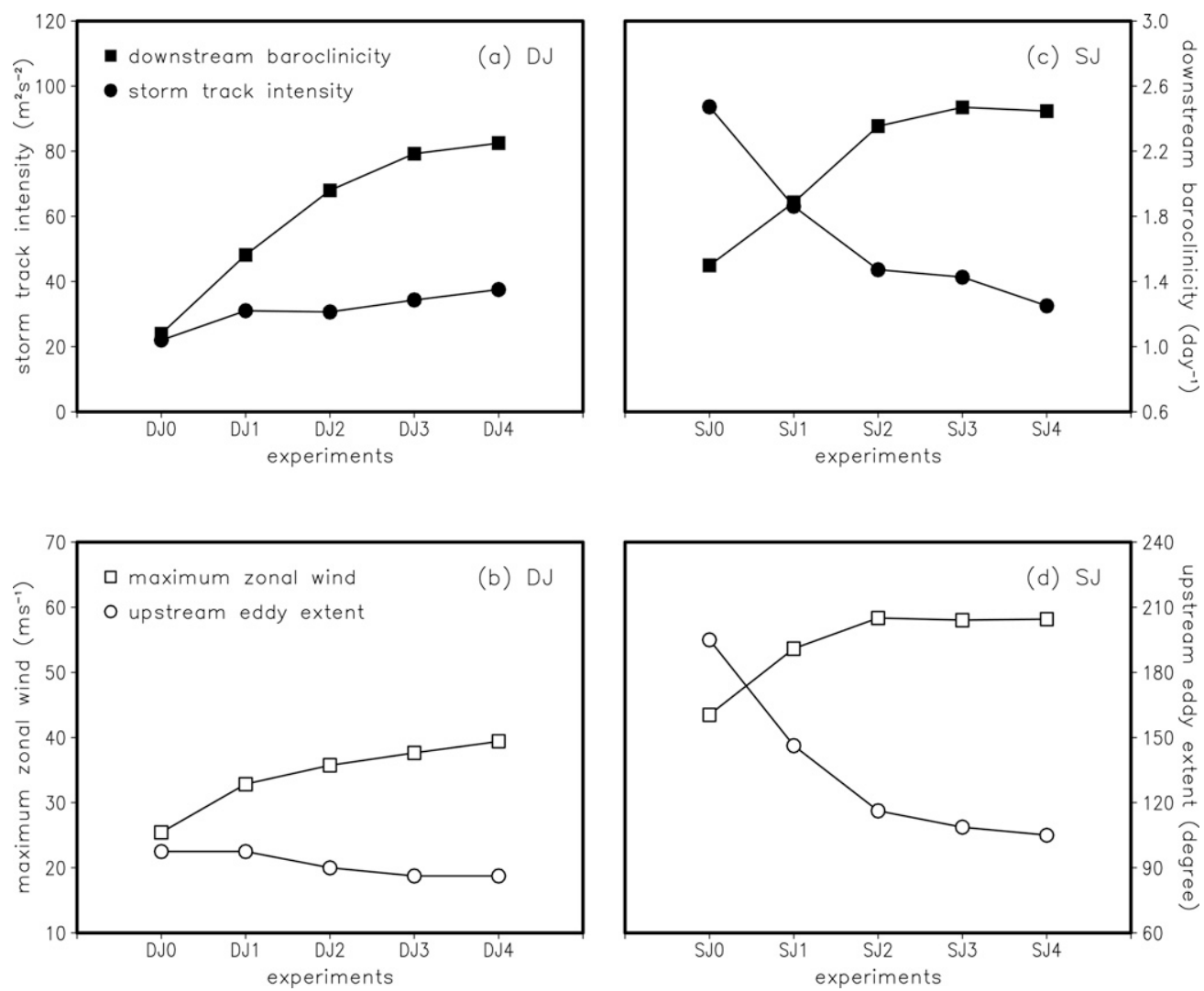

FIG. 4. Summary of the (a), (b) DJ and (c), (d) SJ integrations: baroclinicity downstream of the topography averaged over the boxed areas indicated in Figs. $2 \mathrm{~g}$ and $3 \mathrm{~g}$ (closed squares); storm-track intensity averaged over the boxed areas indicated in Figs. $2 \mathrm{~h}$ and $3 \mathrm{~h}$ (closed circles); maximum zonal wind at $250 \mathrm{hPa}$ (open squares); and upstream eddy extent that is measured by one-point lag correlation map (open circles). See section $4 b$ for the definition of upstream eddy extent.

values greater than one indicates that EKE is strengthened by the topography. Here, the spectral analyses are performed for the daily time series of zonal and meridional winds at each grid point, after applying a tapering function that sets the values at the first and last 10 days of the time series to gradually change from 0 to the raw value and vice versa. The resulting EKE spectra at $250 \mathrm{hPa}$ is slightly smoothed by using a normalized Gaussian spectral window with a bandwidth of $5 \Delta \nu$, where $\Delta \nu$ is the unit frequency interval of $2 \pi / 5000$ days. Note that this smoothing process does not change total EKE integrated over the frequency. The smoothed spectra is then integrated from $15^{\circ}$ to $65^{\circ} \mathrm{N}$ with a cosine latitude weight to obtain a longitudinal distribution of midlatitude EKE on the frequency domain.

In the SJ2 integration (Fig. 6b), high frequency eddies are suppressed by the presence of topography, with the gratest suppression occurring around the topography. This is consistent with the storm-track response (Fig. 3h). However, low frequency eddies (i.e., for frequencies shorter than $0.05 \mathrm{day}^{-1}$ or periods longer than
20 days) are substantially enhanced. Although eddies around 0.06 day $^{-1}$ frequency are weakened, the intermediate frequency eddies around 0.09 day $^{-1}$ frequency are also strengthened. It is this strengthening of intermediate and low frequency eddies by the topography that leads to less dramatic changes in total EKE, compared to the high frequency EKE.

The longitudinally averaged EKEs are presented in side panels to the right of each frame. It can be seen that the EKE spectrum of the SJ0 integration has a distinct scale separation, that is, significant spectral peaks around the frequencies of $0.06,0.15$, and 0.25 day $^{-1}$. These peaks completely disappear when topography is introduced; the EKE spectrum then closely resembles a red noise spectrum. Son et al. (2008) indicated that stationary eddies excited by the topography weaken a meridional gradient of the potential vorticity (PV), resulting in large particle displacements and more frequent wave breaking. The reddening of the EKE spectra is likely due to these breaking waves. Swanson et al. (1997) indicated that breaking waves 


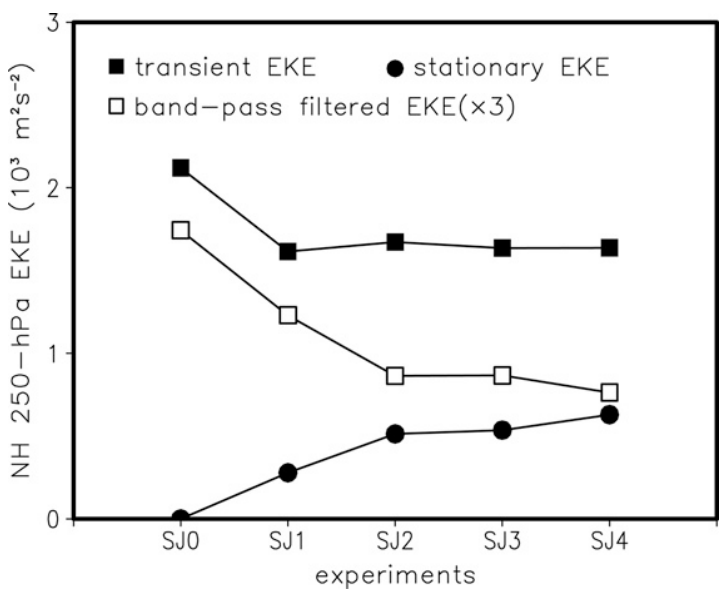

FIG. 5. EKE at $250 \mathrm{hPa}$ integrated over the model $\mathrm{NH}$ for the SJ integrations: transient (squares) and stationary (circles) eddy components. The bandpass-filtered EKE is separately shown with open squares, after multiplied by 3 . The zonal-mean EKE is integrated in latitude with a cosine latitude weight.

tend to lower the frequency and lengthen the eddy scale, and Benedict et al. (2004) showed observational evidence for this. Needless to say, there might be other processes that generate low frequency eddies, but a detailed investigation is beyond the scope of this study.

The ratio of EKE spectra for the DJ integrations is exhibited in Fig. 6a. For almost all frequency bands, eddies are strengthened by the topography: although the strengthening occurs only downstream, it is more than enough to compensate for the weakening of eddies upstream. Exceptions are found around the 0.05-0.1 day ${ }^{-1}$ frequency band at which eddies are to some degree suppressed. This weakening is again associated with reddening in the EKE spectra by topography, as can be inferred from the right column.

\section{Mechanisms}

The physical mechanisms that might determine stormtrack intensity in our integrations are examined in this section. The emphasis is placed on the weakening storm tracks in the SJ integrations with topography. Since similar behavior (weaker storm tracks for stronger baroclinicity) is found in observations, we first review the mechanisms proposed in the previous studies.

The annual cycle of the Pacific storm tracks exhibits a marked minimum during midwinter when the baroclinicity is at a maximum (Nakamura 1992). This so-called midwinter suppression of the Pacific storm tracks has been extensively examined in the past [see Chang et al. (2002) for a review]. Several hypotheses have been proposed: (i) an overly strong jet during midwinter may not allow enough time for eddies to interact with surface baroclinicity (Nakamura 1992); (ii) a very sharp jet (Harnik and Chang 2004) and the associated barotropic wind shear (Although Deng and Mak 2005) may reduce baroclinic eddy growth during midwinter; (iii) the reduction in upstream eddy seeding-feeding may be responsible for the weakening in storm tracks (Orlanski 1998; Zurita-Gotor and Chang 2005); and (iv) diabatic heating may dissipate eddy energy during midwinter (Chang 2001).

While hypotheses (i) and (ii) imply that storm-track intensity is primarily affected by the strength and shape of the jet, (iii) suggests that it is modulated by wave packets and the associate downstream development. In (a) DJ2/DJO EKE at $250 \mathrm{hPa}$

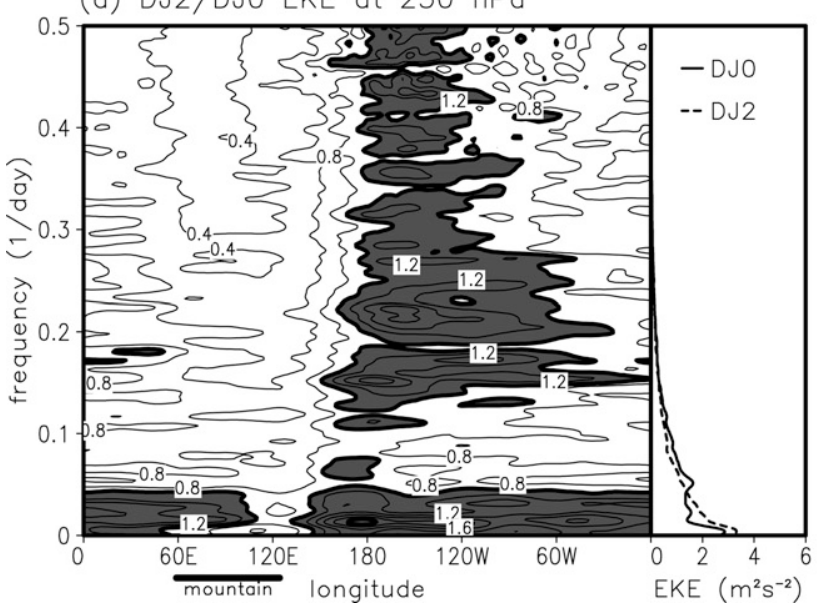

(b) SJ2/SJO EKE at $250 \mathrm{hPa}$

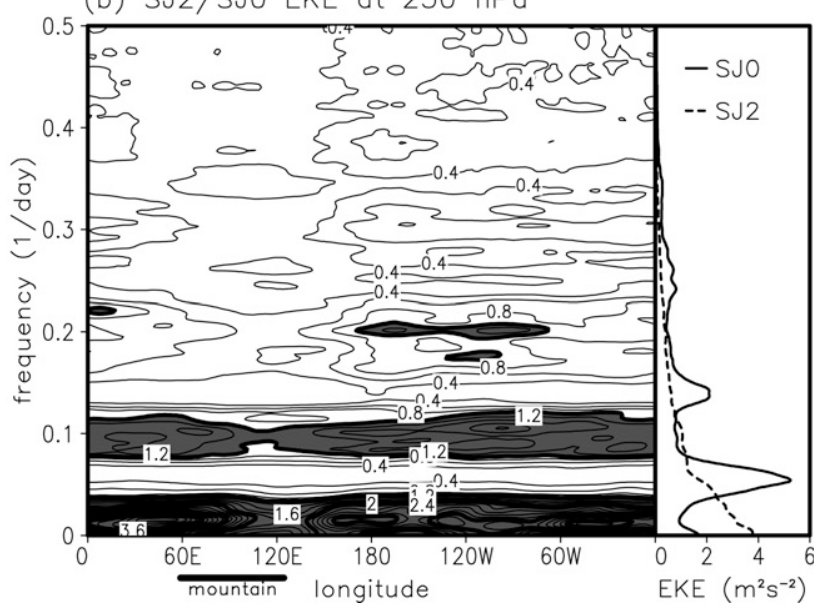

FIG. 6. Latitudinally integrated $250-\mathrm{hPa}$ EKE in the frequency domain: EKE ratio of the (a) DJ2 to DJ0 and (b) SJ2 to SJ0 integrations. CI is 0.4; values greater than 1 are shaded. Longitudinally averaged EKE is also shown in the right-hand side for both control (solid) and topography (dashed) integrations. See the text for details. 

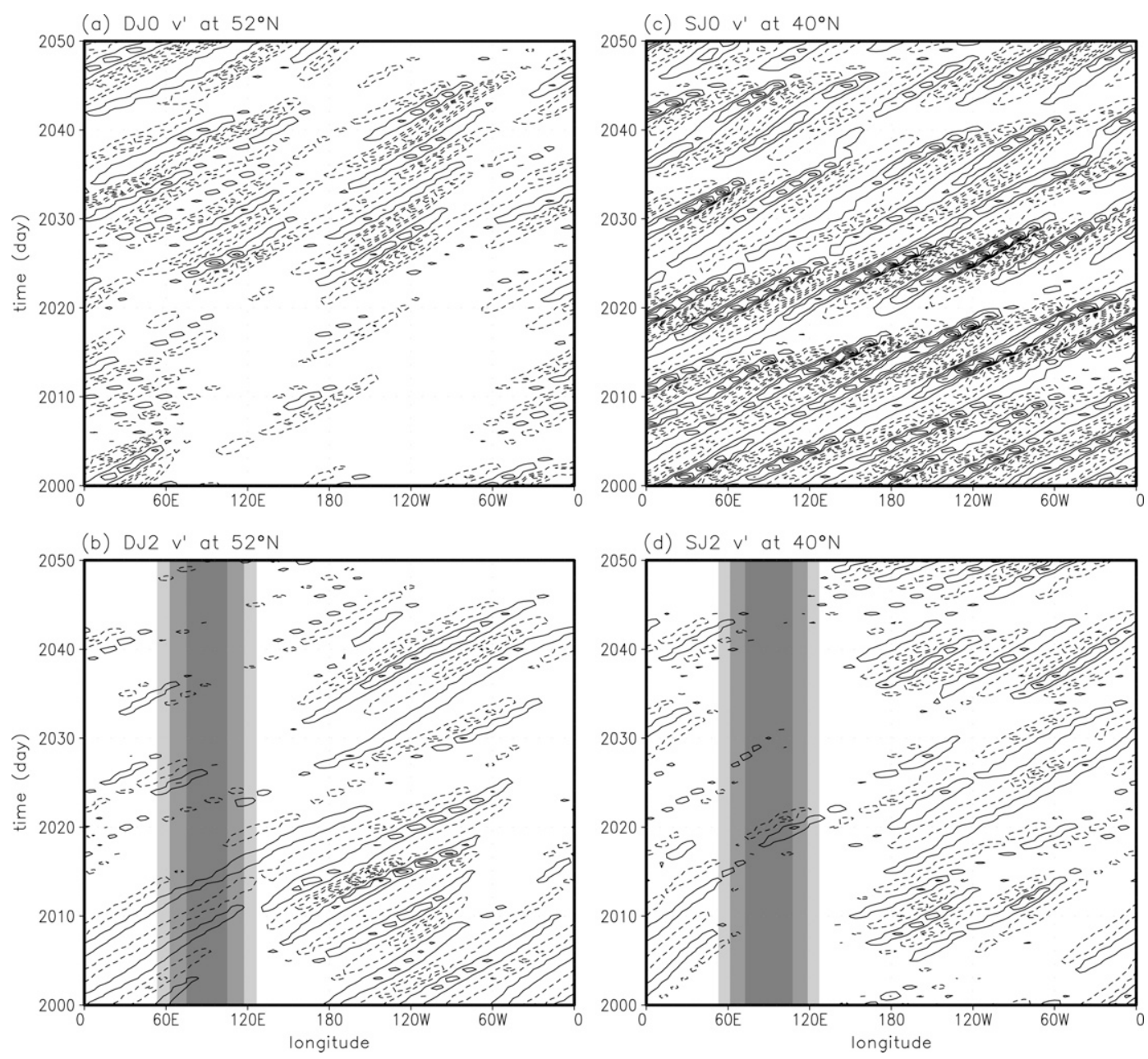

FIG. 7. Hovmöller diagram for the bandpass-filtered eddy meridional wind at $250 \mathrm{hPa}$ for the (a) DJ0, (b) DJ2, (c) SJ0, and (d) SJ2 integrations. A reference latitude is set to (a), (b) $52^{\circ} \mathrm{N}$ and (c), (d) $40^{\circ} \mathrm{N}$ referring to the jet axis. CI is $5 \mathrm{~m} \mathrm{~s}^{-1}$, zero lines omitted; shading in (b) and (d) denotes topography.

contrast, (iv) emphasizes the importance of moist processes. As our model does not include moist processes, we focus here on the possible impact of changes in the jet and wave packets on the storm-track intensity.

\section{a. Westerly jets}

As briefly stated above, an overly strong and narrow jet may result in weaker storm tracks regardless of the baroclinicity. The westerly jets in the SJ integrations are, indeed, strengthened by topography (Fig. 4d). However, their changes are much weaker than those in storm-track intensity (Fig. 4c). For instance, the maximum zonal wind at $250 \mathrm{hPa}$ increases about $8 \%$ from the SJ1 to SJ2 integrations, whereas storm-track intensity decreases by $30 \%$. The structure of the jet is also qualitatively similar in the two integrations (not shown). These results suggest that it is not the westerly jet that primarily modulates storm-track intensity in the SJ integrations. Further evidence will be presented later from the sensitivity integrations in section $5 \mathrm{c}$.

\section{b. Wave packets}

The downstream development is quite sensitive to the structure of wave packets. It is generally strong when packets are organized in the zonal direction. If the wave packets were disorganized or radiate in the meridional direction, their efficiency would be very weak as the eddies seeded far upstream are unlikely to reach the target area.

The zonal structure of wave packets is exhibited in Figs. 7a,c with Hovmöller diagrams of the bandpassfiltered eddy meridional wind at $250 \mathrm{hPa}$. As expected from the differences in internal variability (Son and Lee 2006), structure of the wave packets varies substantially 

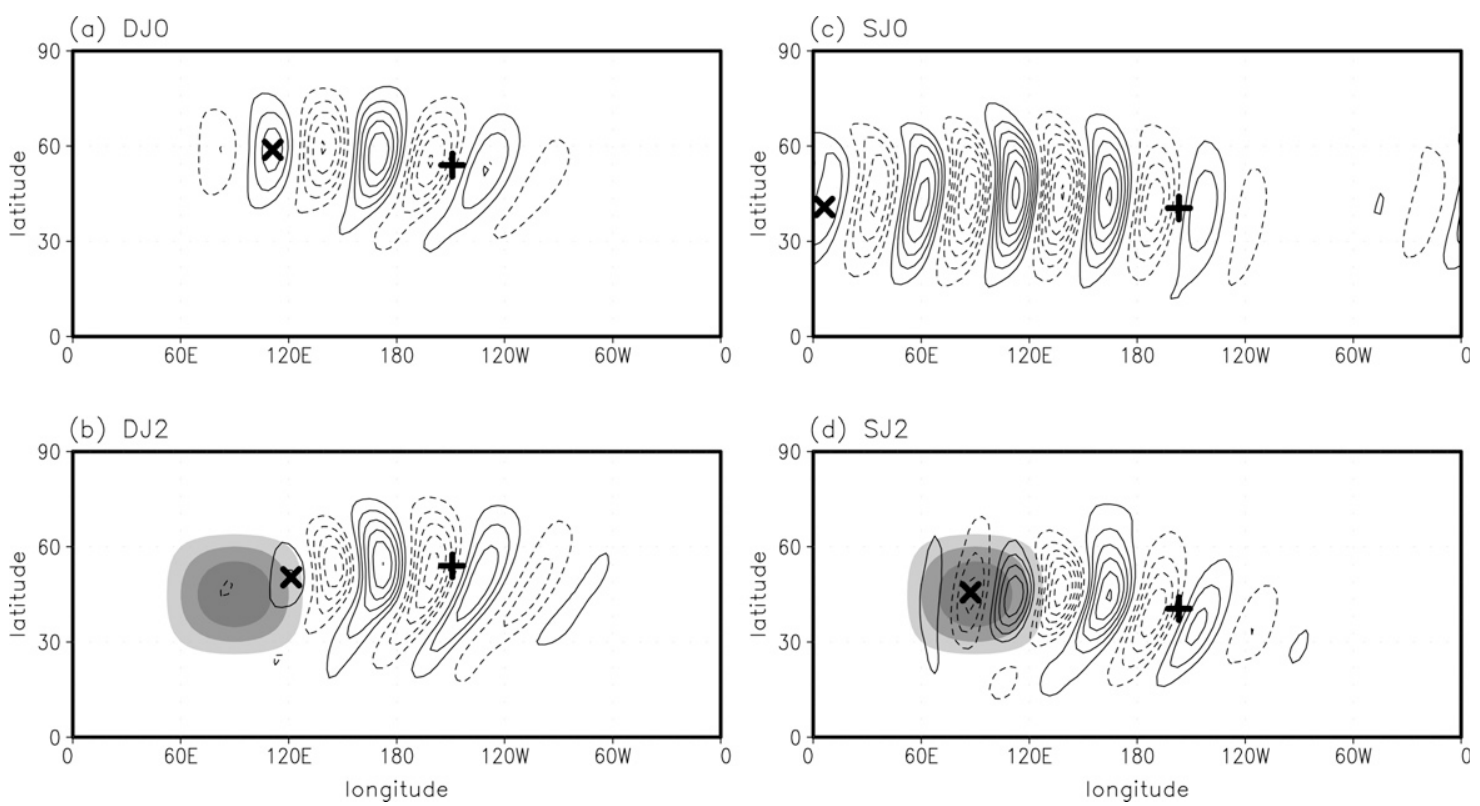

FIG. 8. One-point lag correlation of the bandpass-filtered eddy meridional wind at $250 \mathrm{hPa}$ for the (a) DJ0, (b) DJ2, (c) SJ0, and (d) SJ2 integrations: Correlation coefficients are shown at lag 3 days, corresponding to 3 days before maximum eddy activity at the storm-track centers $(+)$. This time lag is chosen to show upstream structure of the wave packets. The $\times$ marks indicate the leftmost center of the correlation coefficients greater than 0.2 . CI is 0.1 , zero lines omitted; shading in (b) and (d) denotes topography.

between the two integrations. In the DJ0 integration, the packets form occasionally and are maintained for a relatively short time period (Fig. 7a). In contrast, those in the SJ0 integration are highly organized in the zonal direction and often traverse a whole hemisphere without losing amplitude and structure (Fig. 7c).

The less organized zonal wave packets in the DJ0 integration (Fig. 7a) essentially result from the fact that waves tend to propagate equatorward. The twodimensional structure of such wave packets is presented in Fig. 8 by means of a one-point lag-correlation map. Correlation coefficients are calculated for the bandpass-filtered eddy meridional wind at every grid point against reference points ( + in Fig. 8) with a 3-day time lag. It can be seen that wave packets in the DJ0 integration (Fig. 8a) have a significant tilt in the northeast to southwest direction, which indicates equatorward wave propagation. This is in distinct contrast to the wave packets in the SJ0 integration (Fig. 8c), which are largely confined to the zonal direction. Qualitatively similar results are also found when unfiltered data are used (see Fig. 9 of Son et al. 2008).

The fact that wave packets in the SJ0 integration are well organized in the zonal direction (Figs. 7c and 8c) suggests that storm tracks may be strongly affected by far-upstream eddies through eddy seeding-feeding processes. The one-point correlation map (Fig. 8c), indeed, shows that storm-track eddies in the SJ0 integration are correlated with eddy activity even at $30^{\circ} \mathrm{W}$, which is $230^{\circ}$ upstream of the storm-track center. This significant connection to the upstream eddies provides a possible explanation for why storm tracks in the SJ0 integration are much stronger than those in the DJ0 integration. Although the baroclinicity is comparable in the two integrations (Figs. 2c and 3c), the storm tracks in the SJ0 integration are about four times stronger than those in the DJ0 integration (Figs. 2d and 3d).

The different impacts of topography in the DJ and SJ storm tracks can also be related to the spatial structure of wave packets. In the DJ integrations, topography does not change the qualitative structure of the wave packets (cf. Figs. 8a and 8b). Storm tracks are thus simply intensified by the topographically enhanced baroclinicity. It is, however, important to note that the storm tracks are only weakly sensitive to the baroclinicity in the DJ integrations (Fig. 4a). The storm-track intensity increases about 1.5 times from the DJ0 to DJ4 integrations, whereas baroclinicity changes by about four times. This weak response presumably results from the equatorward wave radiation, which is enhanced by the topography (e.g., see the stronger northeast to southwest tilt in the subtropics in Fig. 8b). Since a large fraction of the eddies forced by the enhanced baroclinicity is refracted away before reaching the storm-track 
region, one does not expect a linear intensification of storm tracks relative to baroclinicity downstream of the topography.

Unlike in the DJ integrations, the wave packets in the SJ integrations are significantly modified by topography. Most of all, they become highly disorganized and often break up around the topography (Fig. 7d). This disorganization results from the fact that topography changes the background flow such that eddies excited upstream of the topography propagate largely equatorward. The one-point correlation for the SJ2 integration (Fig. 8d) shows a clear tilting in the northeast to southwest direction, as seen in the DJ integrations. Because of this enhanced equatorward wave radiation, stormtrack eddies may not be effectively fed by eddies that are seeded far upstream (cf. bold $\times$ marks in Figs. $8 \mathrm{c}$ and $8 \mathrm{~d}$ ). It is likely that this weakening of the eddy seeding-feeding process (or downstream development) leads to weaker storm tracks in the SJ integrations with topography.

\section{c. Downstream development}

To gain more physical insight, downstream development is next investigated with wave activity fluxes. We employ the formulas proposed by Takaya and Nakamura (2001). Their wave activity flux is conserved for an adiabatic and inviscid atmosphere, and more importantly each budget term is uniquely defined without any spatial or temporal averaging. Although the eddy energy budget has been widely used for downstream development analyses (e.g., Orlanski and Katzfey 1991), it has been known that energy flux and conversion terms are not uniquely defined (Plumb 1983) and are strongly dependent on wave phase (Takaya and Nakamura 2001).

By combining a normalized eddy enstrophy and eddy energy in the quasigeostrophic framework, Takaya and Nakamura showed that wave activity pseudomomentum $(M)$ and its phase-independent flux $(\mathbf{W})$ can be defined locally. In the presence of nonconservative forcing $D$, a tendency equation for $M$ is

$$
\frac{\partial M}{\partial t}+\nabla \cdot \mathbf{W}=D
$$

The definition of each term is given in the appendix. Here, we briefly discuss how the above equation is related to downstream development.

The horizontal components of $\mathbf{W}$ relative to the local phase speed [the first two terms on the right-hand side of (A3), hereafter $W_{1}$ and $\left.W_{2}\right]$ are associated with ageostrophic geopotential flux in Orlanski and Katzfey (1991) but have no phase dependence. As such, one may expect an active downstream development when $W_{1}$ is strong and well-organized in the zonal direction. The vertical component of $\mathbf{W}$ (hereafter $W_{3}$ ) is associated with eddy heat flux and negative values indicate upward flux. As this term is related to baroclinic energy conversion (negative $W_{3}$ corresponds to available potential energy conversion from the mean flow to the disturbances), it can be useful for identifying baroclinic eddy growth.

Figure 9a shows time-mean bandpass-filtered wave activity pseudomomentum $M$ averaged over the latitudes of maximum storm track for the DJ integrations. It is found that, in the presence of topography, wave activity is strengthened downstream of the mountain but weakened upstream-as is storm-track intensity (Figs. 2d,h). Qualitatively similar responses are also found if one examines eddy enstrophy and eddy energy separately (not shown), suggesting that modification of storm-track eddies by the topography is quite robust. In Fig. 9d, time-mean bandpass filtered $M$ for the SJ integrations is presented. The sensitivity of $M$ to the topography is again consistent with that of storm-track intensity shown in Figs. 3d,h.

The variability of $M$ downstream of the topography and the associated $\mathbf{W}$ are examined by means of composite analyses with respect to the $M$ averaged over the area $45^{\circ}-65^{\circ} \mathrm{N}\left(30^{\circ}-50^{\circ} \mathrm{N}\right), 160^{\circ}-140^{\circ} \mathrm{W}$ for the DJ (SJ) integrations. The local extrema of the area-mean $M$, which is greater than one standard deviation with no secondary maxima in \pm 3 days, are selected. With these criteria, a total of $195,176,151$, and 125 days are identified for the DJ0, DJ2, SJ0, and SJ2 integrations, respectively. Figure 9 shows composite $\left(W_{1}, W_{2}\right)$ vectors at $250 \mathrm{hPa}$ and $W_{3}$ at $550 \mathrm{hPa}$. Since $\mathbf{W}$ is related to the tendency of $M$, the fluxes are shown for one day before the maximum $M$ downstream of the topography. Note also that $W_{3}$ is multiplied by -1 so that positive values represent upward fluxes, indicating baroclinic eddy growth.

In both DJ0 and DJ2 integrations, wave activity fluxes exhibit strong convergence downstream of the topography (Fig. 9b,c). However, they are confined within a limited area, and the contribution by farupstream wave fluxes is essentially absent. Furthermore, the location of maximum wave flux vectors coincides with that of baroclinic energy conversion (see contour lines). These results suggest that storm-track eddies in the DJ integrations are primarily affected by wave fluxes that are excited by local baroclinicity in the low troposphere and then propagate upward and eastward.

The wave activity fluxes in the SJ0 integration are very different (Fig. 9e): they are remarkably well organized in the zonal direction. Although wave activity 
(a) DJO \& DJ2 $\bar{M}$ at $45-65^{\circ} \mathrm{N}$

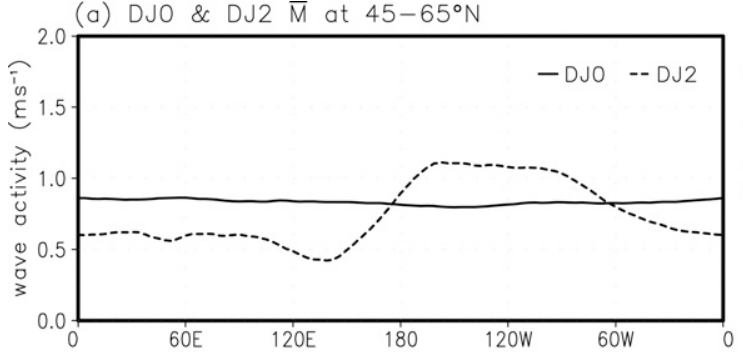

(b) DJO $250 \mathrm{hPa} W_{1,2} \& 550 \mathrm{hPa}-\mathrm{W}_{3}$

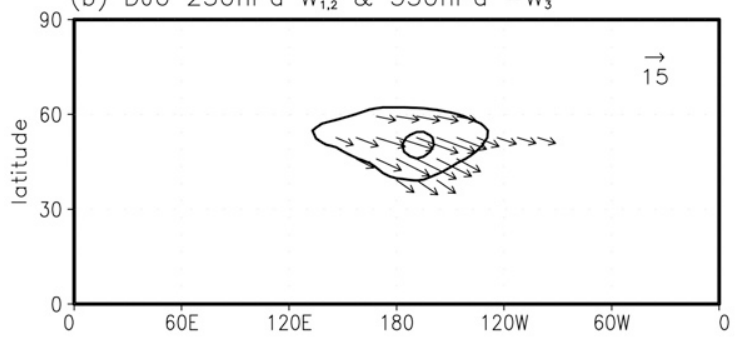

(c) DJ2 $250 \mathrm{hPa} W_{1,2} \& 550 \mathrm{hPa}-\mathrm{W}_{3}$

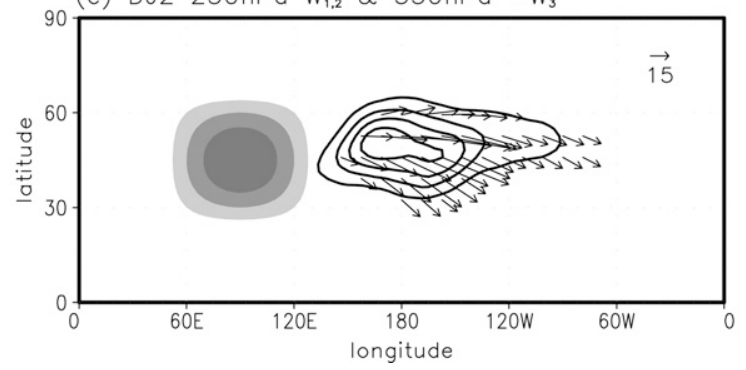

(d) SJO \& SJ2 $\bar{M}$ at $30-50^{\circ} \mathrm{N}$

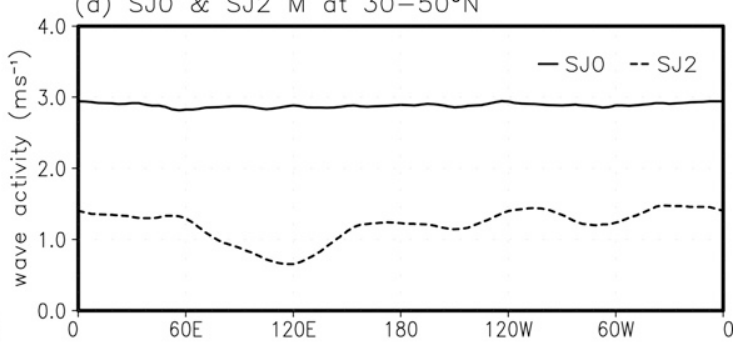

(e) SJO $250 \mathrm{hPa} \mathrm{W}_{1,2} \& 550 \mathrm{hPa}-\mathrm{W}_{3}$

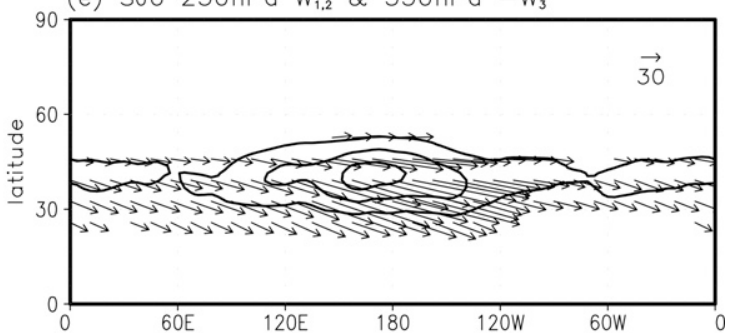

(f) SJ2 $250 \mathrm{hPa} W_{1,2} \& 550 \mathrm{hPa}-\mathrm{W}_{3}$

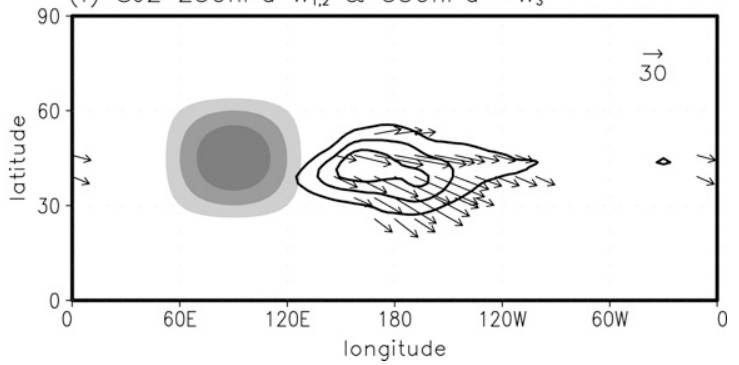

FIG. 9. (top) Time-mean bandpass-filtered $M$ for (a) the DJ integrations averaged from $45^{\circ} \mathrm{N}$ to $65^{\circ} \mathrm{N}$ and for (d) the $\mathrm{SJ}$ integrations averaged from $30^{\circ} \mathrm{N}$ to $50^{\circ} \mathrm{N}$. (middle, bottom) Composite $\left(W_{1}, W_{2}\right)$ vectors at $250 \mathrm{hPa}$ and composite $W_{3}$ at $550 \mathrm{hPa}$ for the (b) DJ0, (c) DJ2, (e) SJ0, and (f) SJ2 integrations. Vectors are shown for every three grid points only when amplitudes are greater than the unit vector indicated in each panel. CI for $W_{3}$ is $0.5 \mathrm{~Pa} \mathrm{~m} \mathrm{~s}{ }^{-2}$, zero lines omitted; shading in (c) and (f) denotes topography. Although not shown, all composite vectors and contours are statistically significant at the $95 \%$ confidence level. See text for the definition of symbols and composite method.

over the reference area $\left(30^{\circ}-50^{\circ} \mathrm{N}, 160^{\circ}-140^{\circ} \mathrm{W}\right)$ is largely driven by maximum wave flux convergence there, it is also highly correlated with wave activity flux far upstream. The contribution by upstream waves is even clearer at lag -3 days (not shown), providing evidence that downstream development is, indeed, playing a significant role in maintaining storm-track eddies. In the presence of topography, however, organized wave activity flux disappears (Fig. 9f). It turns into a very localized pattern, as in the DJ0 and DJ2 integrations, indicating much weaker downstream development.

It should be noted that the overall pattern of wave activity flux in Fig. 9 is qualitatively similar to that of the one-point correlation map in Fig. 8. The zonal coherence of wave fluxes is well captured by lag correlations. The latitudinal tilt in the correlation map is also consistent with the wave flux vector, that is, southwest- northeast tilt in the low and midlatitudes for the equatorward $\mathbf{W}$ and weak northwest-southeast tilt in the high latitudes for the weak poleward $\mathbf{W}$. This consistency allows us to quantify the downstream development by the zonal coherence of eddies in the correlation map, as discussed below.

The efficiency of downstream development is estimated by measuring the extent of upstream eddy seeding (hereafter the upstream eddy extent). By using the one-point lag-correlation map (Fig. 8), upstream eddy extent is defined as the longitudinal distance between the leftmost center of correlation coefficient ${ }^{4}>0.2$ (bold $\times$ in Fig. 8) and the storm-track center (bold + in Fig. 8).

\footnotetext{
${ }^{4}$ Although the results are quantitatively sensitive to the choice of threshold value (e.g., correlation coefficient 0.3 , instead of 0.2 ), they are qualitatively robust regardless of the threshold value.
} 
The results are summarized in Figs. $4 b, d$. For the SJ integrations (Fig. 4d), it can be seen that the changes in storm-track intensity conform to the upstream eddy extent remarkably well; that is, stronger storm tracks result from a longer upstream eddy extent. The small changes in storm-track intensity among the $\mathrm{SJ} 2, \mathrm{SJ} 3$, and SJ4 integrations are also well captured by the changes in upstream eddy extent. This supports the idea that storm-track intensity in the SJ integrations is primarily controlled by downstream development.

\section{d. Sensitivity tests}

To show that the results just described are robust, we have performed a number of sensitivity tests by varying the shape and location of the mountain for the DJ2 and SJ2 integrations. As described in section 2, the latitudinal or longitudinal width of the topography is reduced by half or the location of the topography is moved $10^{\circ}$ north or south. The resulting storm tracks are illustrated in Fig. 10. It can be seen that the overall shape and intensity of the storm tracks are qualitatively similar to those in the base integrations. Storm tracks in all DJ2 sensitivity integrations (Figs. 10a-d) are stronger than those in the DJ0 integration (Fig. 2d). Likewise, storm tracks in all SJ2 sensitivity integrations (Figs. $10 \mathrm{e}-\mathrm{h})$ are weaker than those in the SJ0 integration (Fig. 3d).

The relationship between storm-track intensity and other variables of interest is summarized in Fig. 11. The storm tracks in the DJ2 sensitivity integrations are only weakly sensitive to the topography, as in the DJ base integrations. The results of the SJ2 sensitivity integrations are also qualitatively similar to those of the SJ base integrations. Again, the intensity of the storm tracks is closely related to upstream eddy extent (cf. Figs. 11c and 11d). The changes in the westerly jet are quite weak and, more importantly, inconsistent with those in the storm-track intensity. For instance, the jet strength is about the same in the SJ2NS and SJ2 integrations, although the storm-track intensities are substantially different. These results confirm that storm tracks in the strong single-jet state are primarily modulated by downstream development.

Sensitivity tests are also carried out for different background flows (Fig. 12). Five different background flows are generated by altering the $T_{e}$ forcing gradually from SJ0 (Fig. 1a) to DJ0 (Fig. 1c). These integrations correspond to the ones along the diagonal axis E in SL05 (see their Fig. 4), and are denoted by A0 to G0 in this study. Note that the B0 and F0 integrations are identical to the SJ0 and DJ0 integrations, shown here for comparison. For these background flows, the topographic impact is examined by adding a mountain identical to the one in the DJ2 and SJ2 integrations. Figure 13 exhibits the storm-track intensity and one-point correlation map for both (left) no-mountain and (right) mountain integrations. It can be seen that the storm tracks downstream of the topography are weakened $\sim 0.5$ times in the A2, $\mathrm{B} 2$, and $\mathrm{C} 2$ integrations. This weakening is consistent with the modification of wave coherence or upstream eddy extent by the topography, as can be inferred from the correlation map. In contrast, storm tracks in the F2 and G2 integrations are strengthened $\sim 1.5$ times due to enhanced baroclinicity by the topography.

The above results provide further evidence that the response of storm-track intensity to topography is highly dependent on the background flow: weaker storm tracks for the strong single-jet states (A2, B2, and $\mathrm{C} 2$ integrations) but stronger storm tracks for the weak double-jet states (F2 and G2 integrations). However, the boundary between the two is somewhat blurred. An example is the E0 integration shown in Fig. 13e. Although wave packets are coherent in the zonal direction, the maximum storm-track intensity is essentially unchanged by the presence of topography (Fig. 131). This suggests that the topographic effect on storm-track intensity may not be determined a priori by wave packet characteristics, especially if the background flow is between the strong single-jet and the weak double-jet states (Fig. 12e).

Although not shown, sensitivity tests were also performed by varying the model resolution. For the DJ2 and SJ2 integrations, either the horizontal or vertical resolution is increased by a factor of 2 . The resulting storm-track behavior was found to be qualitatively similar to that in the base integrations, indicating that the results presented here are robust to changes in model resolution.

\section{Summary and discussion}

A series of simple dry GCM integrations shows that the topographic effect on storm-track intensity is highly dependent on the structure of background flow. When the background flow consists of a weak double jet, the topography strengthens the storm track by enhancing baroclinicity downstream of the topography. However, if the background flow is a strong single jet, topography weakens the storm track.

The above opposing impacts of topography are found to be associated with different wave packets in the two background flows. For a weak double jet (DJ) wave packets noticeably propagate equatorward. Since eddies are refracted away before reaching the storm-track region, storm tracks are only weakly affected by the topography; nonetheless, it is evident that storm tracks are 

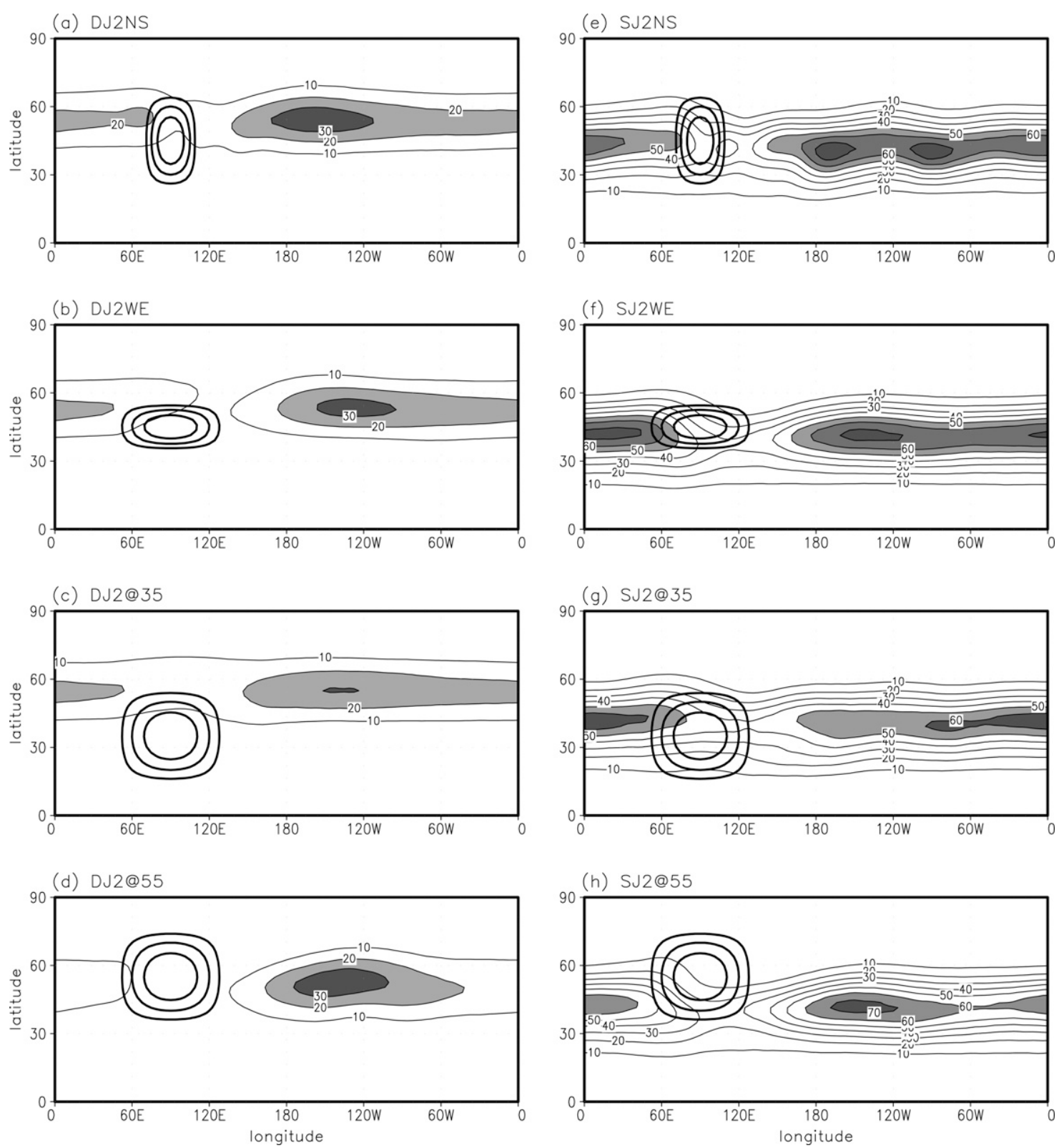

FIG. 10. Storm-track intensity at $250 \mathrm{hPa}$ for the (a)-(d) DJ2 and (e)-(h) SJ2 sensitivity integrations. CI is $10 \mathrm{~m}^{2} \mathrm{~s}^{-2}$; values (a)-(d) $\geq 20$ and (e)-(h) $\geq 50 \mathrm{~m}^{2} \mathrm{~s}^{-2}$ are shaded. In (a)-(h), topography is denoted with thick solid lines as in Figs. $2 \mathrm{~h}$ and $3 \mathrm{~h}$.

intensified by topographically enhanced baroclinicity. In contrast, for a strong single jet (SJ), wave packets persistently propagate in the zonal direction in the absence of topography. The storm-track eddies are thus affected not only by the local baroclinicity but also by far-upstream eddies via downstream development. This leads to storm tracks that are much stronger than those expected from local baroclinicity alone. In the presence of topography, downstream development is markedly weakened as the topography tends to disorganize the wave packets in the zonal direction. It is this weakening in downstream development that causes the weakening in storm tracks for a strong single-jet state, despite the enhanced baroclinicity downstream of the topography.

It should be noted that the characteristics of wave packets are not directly determined by the jet structure but by the associated PV gradient: a strong meridional PV gradient for zonally propagating wave packets versus a weak meridional PV gradient for equatorward 

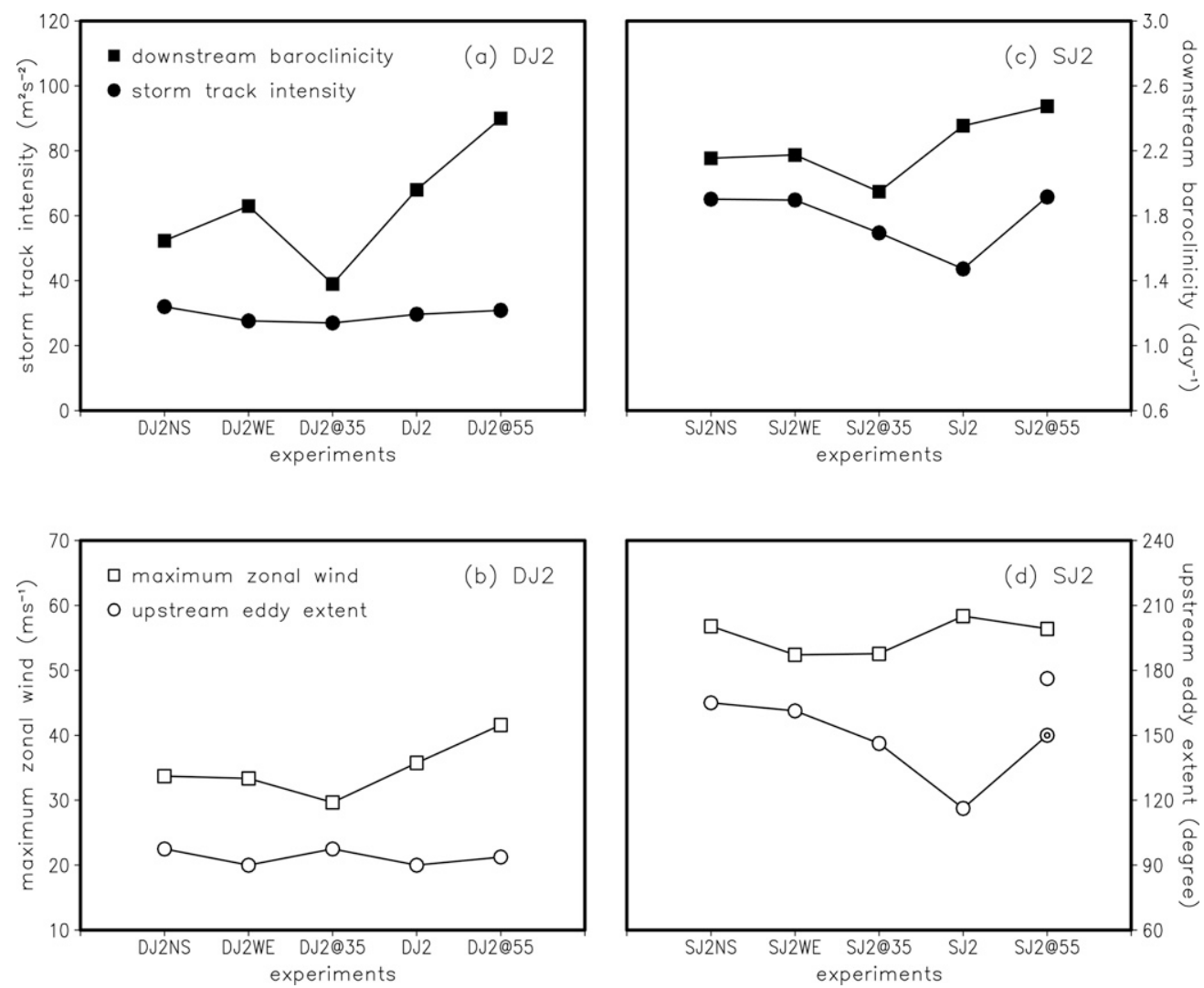

FIG. 11. As in Fig. 4 but for the (a), (b) DJ2 and (c), (d) SJ2 sensitivity integrations. A double circle in (d) denotes the upstream eddy extent in the SJ2@55 integration based on correlation coefficient 0.3 . It is used here because the leftmost closed contour, $>0.2$, is only slightly larger than $0.2(\sim 0.205)$.

propagating wave packets (see also Son and Lee 2006). This suggests that equatorward wave propagation may occur even in the single-jet state if jet strength is too weak to support a strong PV gradient. In this weak single-jet state, storm tracks could be strengthened in the presence of topography. Of course, this possibility could be tested by changing the background flow systematically from a weak to a moderate and then to a strong single jet. However, this type of sensitivity test is difficult to realize because the strength and shape of the jet are mutually dependent (e.g., SL05).

Although this study is aimed at understanding the topographic impact on the storm-track intensity, its impact on storm-track shape is also an interesting subject. It is noticeable that storm tracks in our topography integrations are quite broad, extending over $180^{\circ}$ in longitude (e.g., Figs. 13h-n). Qualitatively similar results have been also found in previous studies that examined topographic impact on high-frequency eddy activity (Yu and Hartmann 1995; Gerber 2005). Such broad storm tracks, however, are quite different from the observed storm tracks in the $\mathrm{NH}$, which are highly localized. There might be several reasons for this dis- crepancy. One of them could be zonal asymmetry in thermal forcing, such as might result from land-sea contrast or latent heating. In fact, by adding both topography and land-sea contrast in a simple GCM, Gerber (2005) was able to generate storm tracks that are quite similar to the observations. Although not examined here, zonally asymmetric thermal forcing would also change storm-track intensity, as discussed by Hoskins and Valdes (1990) and Chang (2001).

The results of this study lend support to the previous modeling study of Zurita-Gotor and Chang (2005). By using a two-layer quasigeostrophic model, they suggested that midwinter suppression of the Pacific storm tracks may be attributed to changes in downstream development. Although weaker storm tracks may result from a strong and sharp jet, they found that this occurs only when background flows are rather unrealistic. The results of our study, which are based on a more realistic model, are largely consistent with their findings and provide further evidence of the important role played by downstream development in regulating storm-track intensity.

This study also provides useful insight into observed 

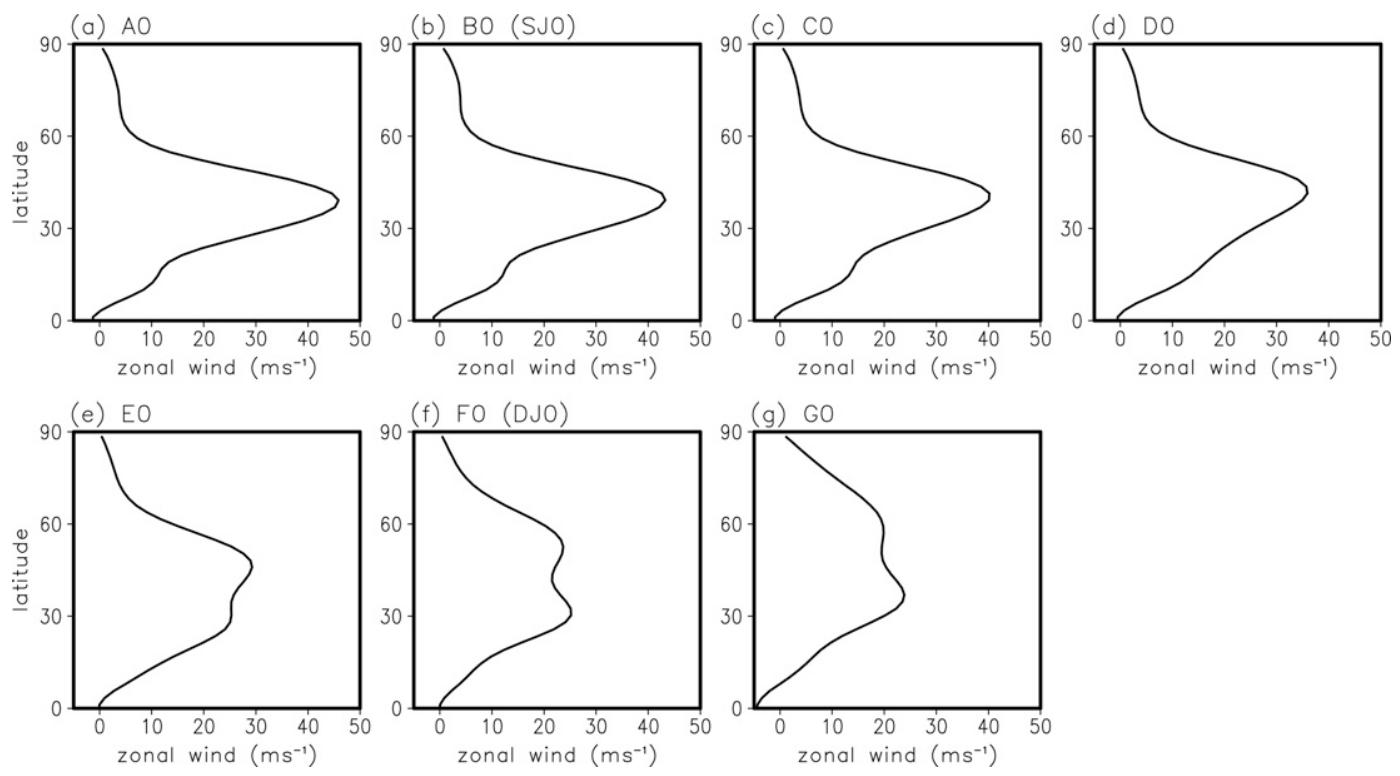

FIG. 12. Time-mean zonal-mean zonal wind at $250 \mathrm{hPa}$ for seven different background flows. Note that the B0 and F0 integrations are identical to the SJ0 and DJ0 integrations, respectively.

storm tracks. The westerly jet over the North Atlantic during $\mathrm{NH}$ winter is similar to the weak double jet in the DJ integrations. Likewise, the westerly jet over the northwestern Pacific is qualitatively similar to the strong single jet in the SJ integrations. Further similarity is also found in the internal variability. Feldstein (1998) showed that poleward propagation of zonal mean flows, accompanied by equatorward wave propagation, is predominantly observed over the North Atlantic sector. Consistent with this, Chang and Yu (1999) found that wave packets over the North Atlantic are less coherent than those over the Asia-Pacific sector, indicating that downstream development is less efficient there (as in the DJ integrations). In this context, the negative relationship between local baroclinicity and storm-track intensity that is found in the SJ integrations but not in the DJ integrations may be compared to the observed midwinter suppression in the Pacific storm tracks but not in the Atlantic storm tracks. Our results then suggest that the different characteristics of the Atlantic and Pacific storm tracks may result from the different background flows rather than details of topography and diabatic processes.

A direct application of our results to the atmosphere, however, requires caution. For instance, Chang (2001) indicated that diabatic heating may be responsible for the relatively weak Pacific storm tracks during midwinter when the baroclinicity is a maximum and wave packet is highly organized. However, this possible impact of diabatic heating is not included in our model, suggesting that our results may not be strictly valid for the Pacific storm track. In addition, although the topography may have different effects in the Atlantic and Pacific storm tracks, it does not explain why the seasonal cycle of the two storm tracks is distinctly different. In this study, the local baroclinicity and the efficiency of downstream development are modulated by topography. This is in contrast with the atmosphere, in which the background flow itself varies over time for a given topography.

It should also be noted that the wave packets in our integrations are much more coherent than in the observations (e.g., Chang and Yu 1999) and persist much longer. As discussed by Son et al. (2008), the decorrelation time scale of the dominant internal variability, defined by the principal component of the leading empirical orthogonal function, is $\sim 50$ days in the SJ0 integration: it is about five times longer than observations. Although time scales are shorter in some of our integrations, they are still longer than 30 days. This suggests that storm-track eddies in our integrations may be less nonlinear than those in the atmosphere, and this may affect the topographic impact on the storm tracks.

A key conclusion of this study is that topography may have different impacts on the Atlantic and Pacific storm tracks. In a future study, we plan to test this hypothesis by using the same model but with more realistic forcing. For instance, Becker and Schmitz (2001) showed that a simple GCM, which is essentially the same as the model employed in this study, is able to reproduce a realistic 

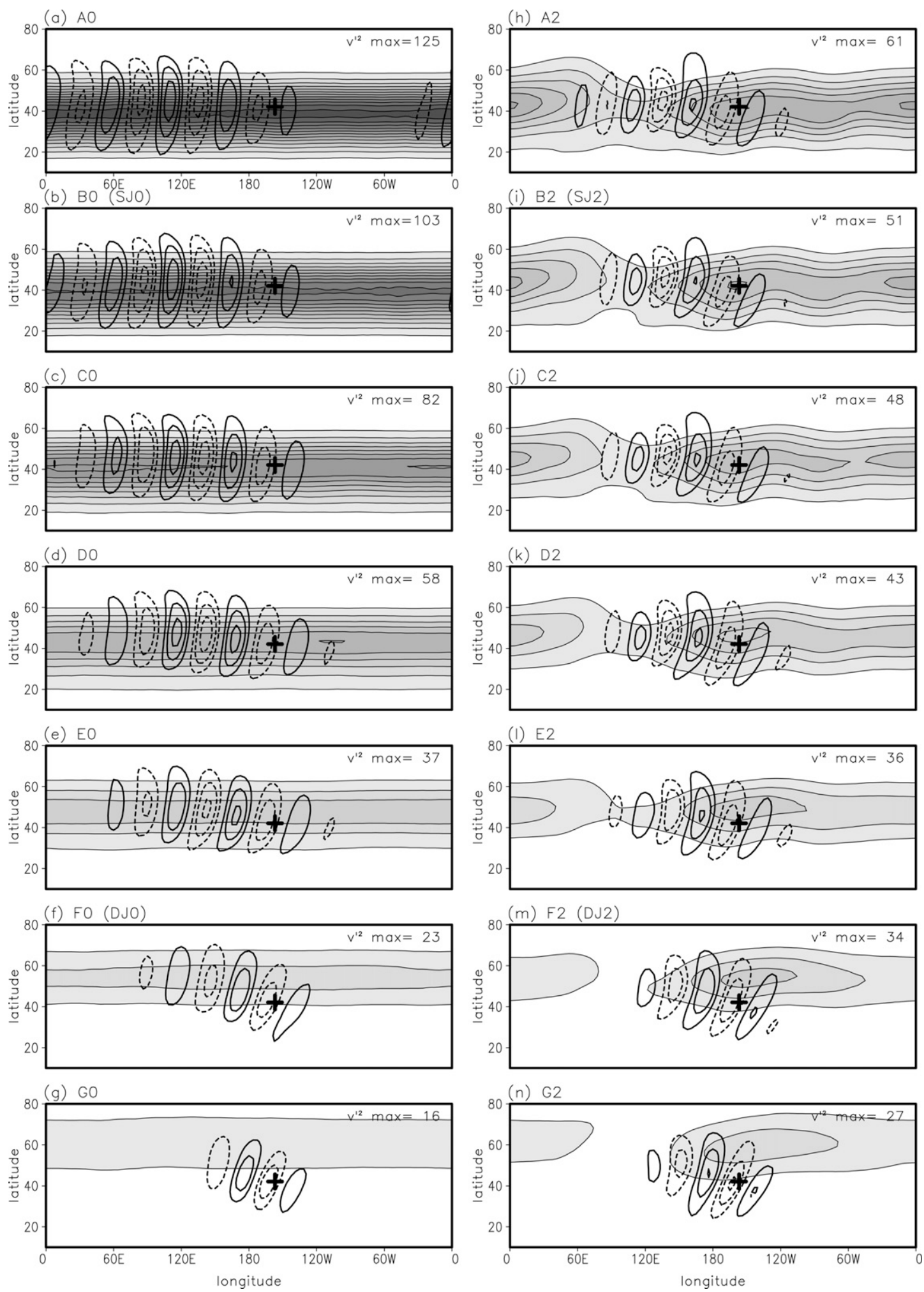

FIG. 13. Storm-track intensity (shading and thin contour lines with $\mathrm{CI}=10 \mathrm{~m}^{2} \mathrm{~s}^{-2}$ ) and one-point lag correlation of the bandpass-filtered eddy meridional wind at $250 \mathrm{hPa}$ (thick solid lines with $\mathrm{CI}=0.2)$ for $(\mathrm{a})-(\mathrm{g})$ no-mountain and (h)-(n) 2-km mountain integrations. Location of the mountain in (h)-(n) is same as in Figs. 2 and 3. Correlation coefficients are calculated with a 3-day time lag as in Fig. 8; reference points are indicated with crosses. Note that the B0, F0, B2, and F2 integrations are identical to the SJ0, DJ0, SJ2, and DJ2 integrations, respectively. 
$\mathrm{NH}$ winter circulation by utilizing a realistic $T_{e}$ profile and topography plus a prescribed latent heating forcing. The first-order response of storm tracks to the topography in the atmosphere can then be tested by varying the topography in such a more realistic model. The possible nonlinearity in the interaction between topographic forcing and midlatitude thermal forcing for maintaining storm tracks could also be addressed.

Acknowledgments. Discussion with Dr. Sukyoung Lee in the early stage of this work is gratefully acknowledged. We also thank Drs. Ming Cai, Jonathon Wright, and Edwin Gerber for helpful comments. This work is supported, in part, by a grant from the U.S. National Science Foundation to Columbia University.

\section{APPENDIX}

\section{Wave Activity Flux in Pressure Coordinates}

Takaya and Nakamura (2001) showed that, in the presence of nonconservative forcing $D$, a equation for $M$ can be written as

$$
\frac{\partial M}{\partial t}+\nabla \cdot \mathbf{W}=D
$$

The wave activity pseudomomentum $M$ in (A1) is

$$
M=\frac{\cos \varphi}{2}\left(\frac{q^{\prime 2}}{2\left|\nabla_{h} \bar{q}\right|}+\frac{e^{\prime}}{|\mathbf{V}|-C_{p}}\right)
$$

where $\varphi$ is the latitude, $q$ the quasigeostrophic potential vorticity, $e$ the quasigeostrophic eddy energy, and $C_{p}$ the phase speed in the direction of geostrophic wind $\mathbf{V}$; the overbar represents the long-term mean and the prime the deviation from that. In pressure coordinates on the sphere, $q$ and $e$ are defined as

$$
\begin{aligned}
q \equiv f & +\frac{1}{a^{2} \cos ^{2} \varphi} \frac{\partial^{2} \psi}{\partial \lambda^{2}}+\frac{1}{a^{2} \cos \varphi} \frac{\partial}{\partial \varphi}\left(\cos \varphi \frac{\partial \psi}{\partial \varphi}\right) \\
& +\frac{\partial}{\partial p}\left(\frac{f_{o}^{2}}{S^{2}} \frac{\partial \psi}{\partial p}\right), \\
e \equiv & \frac{1}{2}\left[\left(\frac{1}{a} \frac{\partial \psi}{\partial \varphi}\right)^{2}+\left(\frac{1}{a \cos \varphi} \frac{\partial \psi}{\partial \lambda}\right)^{2}+\left(\frac{f_{o}}{S} \frac{\partial \psi}{\partial p}\right)^{2}\right] .
\end{aligned}
$$

All symbols are standard: $f$ is the Coriolis parameter, $f_{o}$ the Coriolis parameter at $45^{\circ}, a$ the radius of earth, $\lambda$ the longitude, $\psi$ the streamfunction, and $S^{2}=$ $-\alpha_{o}\left(\partial \ln \theta_{o} / \partial p\right)$ the static stability parameter, where $\alpha_{o}$ and $\theta_{o}$ are the reference specific volume and potential temperature as a function of pressure, respectively.

The wave activity flux $\mathbf{W}$ in (A1) is expressed as

$$
\begin{gathered}
\mathbf{W}=\frac{\cos \varphi}{2|\overline{\mathbf{V}}|}\left(\begin{array}{c}
\frac{\bar{u}}{a^{2} \cos ^{2} \varphi}\left[\left(\frac{\partial \psi^{\prime}}{\partial \lambda}\right)^{2}-\psi^{\prime} \frac{\partial^{2} \psi^{\prime}}{\partial \lambda^{2}}\right]+\frac{\bar{v}}{a^{2} \cos \varphi}\left[\frac{\partial \psi^{\prime}}{\partial \lambda} \frac{\partial \psi^{\prime}}{\partial \varphi}-\psi^{\prime} \frac{\partial^{2} \psi^{\prime}}{\partial \lambda \partial \varphi}\right] \\
\frac{\bar{u}}{a^{2} \cos \varphi}\left[\frac{\partial \psi^{\prime}}{\partial \lambda} \frac{\partial \psi^{\prime}}{\partial \varphi}-\psi^{\prime} \frac{\partial^{2} \psi^{\prime}}{\partial \lambda \partial \varphi}\right]+\frac{\bar{v}}{a^{2}}\left[\left(\frac{\partial \psi^{\prime}}{\partial \varphi}\right)^{2}-\psi^{\prime} \frac{\partial^{2} \psi^{\prime}}{\partial \varphi^{2}}\right] \\
\frac{f_{o}^{2}}{S^{2}}\left\{\frac{\bar{u}}{a \cos \varphi}\left[\frac{\partial \psi^{\prime}}{\partial \lambda} \frac{\partial \psi^{\prime}}{\partial p}-\psi^{\prime} \frac{\partial^{2} \psi^{\prime}}{\partial \lambda \partial p}\right]+\frac{\bar{v}}{a}\left[\frac{\partial \psi^{\prime}}{\partial \varphi} \frac{\partial \psi^{\prime}}{\partial p}-\psi^{\prime} \frac{\partial^{2} \psi^{\prime}}{\partial \varphi \partial p}\right]\right\}
\end{array}\right)+\frac{M C_{p}}{|\overline{\mathbf{V}}|}\left(\begin{array}{c}
\bar{u} \\
\bar{v} \\
0
\end{array}\right) \\
=\left(\begin{array}{c}
W_{1} \\
W_{2} \\
W_{3}
\end{array}\right)+\frac{M C_{p}}{|\overline{\mathbf{V}}|}\left(\begin{array}{c}
\bar{v} \\
\bar{v} \\
0
\end{array}\right) .
\end{gathered}
$$

All analyses are performed for the bandpass-filtered $\psi^{\prime}$. In (A2) and (A3) the local phase speed $C_{p}$ is calculated with the method used by Chang and Yu (1999) and Takaya and Nakamura (2001): $\psi^{\prime}$ at each grid point is correlated with $\psi^{\prime}$ at all other grid points with \pm 1 -day time lag, and then the distance between the maximum correlations at positive and negative time lags is measured. The resulting phase speed vector is projected onto the time-mean local geostrophic wind $\mathbf{V}$ to obtain $C_{p}$.

\section{REFERENCES}

Becker, E., and G. Schmitz, 2001: Interaction between extratropical stationary waves and the zonal mean circulation. $J$. Atmos. Sci., 58, 462-480.

Benedict, J. J., S. Lee, and S. B. Feldstein, 2004: Synoptic view of the North Atlantic Oscillation. J. Atmos. Sci., 61, 121144.

Blackmon, M. L., 1976: A climatological spectral study of the 500$\mathrm{mb}$ geopotential height of the Northern Hemisphere. J. Atmos. Sci., 33, 1607-1623.

Broccoli, A. J., and S. Manabe, 1992: The effects of orography on 
midlatitude Northern Hemisphere dry climates. J. Climate, $\mathbf{5}$, 1181-1201.

Chang, E. K. M., 2001: GCM and observational diagnoses of the seasonal and interannual variations of the Pacific storm track during the cool seasons. J. Atmos. Sci., 58, 1784-1800.

— and I. Orlanski, 1993: On the dynamics of a storm track. $J$. Atmos. Sci., 50, 999-1015.

— and D. B. Yu, 1999: Characteristics of wave packets in the upper troposphere. Part I: Northern Hemisphere winter. $J$. Atmos. Sci., 56, 1708-1728.

_ S. Lee, and K. L. Swanson, 2002: Storm track dynamics. J. Climate, 15, 2163-2183.

Cook, K. H., and I. M. Held, 1992: The stationary response to large-scale orography in a general circulation model and a linear model. J. Atmos. Sci., 49, 525-539.

Deng, Y., and M. Mak, 2005: An idealized model study relevant to the dynamics of the midwinter minimum of the Pacific storm track. J. Atmos. Sci., 62, 1209-1225.

Feldstein, S. B., 1998: An observational study of the intraseasonal poleward propagation of zonal mean flow anomalies. J. Atmos. Sci., 55, 2516-2529.

Frederiksen, J. S., 1983: Disturbances and eddy fluxes in Northern Hemisphere flows: Instability of three-dimensional January and July flows. J. Atmos. Sci., 40, 836-855.

Gerber, E. P., 2005: A dynamical and statistical understanding of the NAO and annular modes. Ph.D. thesis, Princeton University, $242 \mathrm{pp}$.

Harnik, N., and E. K. M. Chang, 2004: The effects of variations in jet width on the growth of baroclinic waves: Implications for midwinter Pacific storm-track variability. J. Atmos. Sci., 61, 23-40.

Held, I. M., M. Ting, and H. Wang, 2002: Northern winter stationary waves: Theory and modeling. J. Climate, 15, 21252144.

Hoskins, B. J., and P. J. Valdes, 1990: On the existence of storm tracks. J. Atmos. Sci., 47, 1854-1864.

— alistic longitudinally varying flow. J. Atmos. Sci., 50, 16611671.

Lee, S., and H.-K. Kim, 2003: The dynamical relationship between subtropical and eddy-driven jets. J. Atmos. Sci., 60, 14901503.

Lee, W.-J., and M. Mak, 1996: The role of orography in the dynamics of storm tracks. J. Atmos. Sci., 53, 1737-1750.
Nakamura, H., 1992: Midwinter suppression of baroclinic wave activity in the Pacific. J. Atmos. Sci., 49, 1629-1642.

Nigam, S., I. M. Held, and S. W. Lyons, 1988: Linear simulation of the stationary eddies in a GCM. Part II: The "mountain" model. J. Atmos. Sci., 45, 1433-1452.

Orlanski, I., 1998: Poleward deflection of storm tracks. J. Atmos. Sci., 55, 2577-2602.

, and J. Katzfey, 1991: The life cycle of a cyclone wave in the Southern Hemisphere. Part I: Eddy energy budget. J. Atmos. Sci., 48, 1972-1998.

Pierrehumbert, R. T., 1984: Local and global baroclinic instability of zonally varying flow. J. Atmos. Sci., 41, 2141-2162.

Plumb, R. A., 1983: A new look at the energy cycle. J. Atmos. Sci., 40, 1669-1688.

Son, S.-W., and S. Lee, 2005: The response of westerly jets to thermal driving in a primitive equation model. J. Atmos. Sci., 62, 3741-3757.

— , and — 2006: Preferred modes of variability and their relationship with climate change. J. Climate, 19, 2063-2075.

,,-- S. B. Feldstein, and J. E. Ten Hoeve, 2008: Time scale and feedback of zonal mean flow variability. J. Atmos. Sci., 65, 935-952.

Swanson, K. L., P. J. Kushner, and I. M. Held, 1997: Dynamics of barotropic storm tracks. J. Atmos. Sci., 54, 791-810.

Takaya, K., and H. Nakamura, 2001: A formulation of a phaseindependent wave-activity flux for stationary and migratory quasigeostrophic eddies on a zonally varying basic flow. $J$. Atmos. Sci., 58, 608-627.

Ting, M., H. Wang, and L. Yu, 2001: Nonlinear stationary wave maintenance and seasonal cycle in the GFDL R30 GCM. $J$. Atmos. Sci., 58, 2331-2354.

Valdes, P. J., and B. J. Hoskins, 1991: Nonlinear orographically forced planetary waves. J. Atmos. Sci., 48, 2089-2106.

Whitaker, J. S., and R. M. Dole, 1995: Organization of storm tracks in zonally varying flows. J. Atmos. Sci., 52, 1178-1191.

Yu, J.-Y., and D. L. Hartmann, 1995: Orographic influences on the distribution and generation of atmospheric variability in a GCM. J. Atmos. Sci., 52, 2428-2443.

Zurita-Gotor, P., and E. K. M. Chang, 2005: The impact of zonal propagation and seeding on the eddy-mean flow equilibrium of a zonally varying two-layer model. J. Atmos. Sci., 62, 22612273. 